\title{
Fluctuating Exchange Rates A Study using the ASIR model
}

\author{
by Z. Margaret Brown and Lawrence Galitz *
}

\section{Introduction}

The extra dimension of risk incurred by insurers writing overseas business may be analysed by comparing solvency ratios and increases in shareholders' funds after a year in which exchange rates remain constant, with the corresponding values after a year in which the insurer's home currency appreciates or depreciates relative to the foreign currencies.

These changes in solvency margins and ratios depend not only on the degree of currency appreciation but also on the strategy adopted by the insurer with regard to the investment of insurance funds and on the economic environment in each country.

A computer simulation model is therefore an appropriate method of investigating the effects of these different factors because of the complexity of the calculations involved. The paper aims to show how the ASIR model can be used in this way by taking three different strategies and three simple economic environments and looking at each combination in turn.

The author would like to thank Mr. C. G. Lloyd, of the Commercial Union Assurance Company Limited, London, for the inspiration given by his paper (2), and for allowing his hypothetical example to be quoted in Section 2. The ASIR model is described in detail in the User's Manual [1].

\section{Methodology}

For the purposes of this study, solvency ratio is defined as the shareholders' funds at the end of the year divided by the premiums written during the year (expressed as a percentage). Assets and liabilities, and premiums in foreign currencies, are converted at the end of year exchange rates.

* Institute of European Finance, Bangor, North Wales, U.K. 
Suppose an insurer's solvency ratio at the beginning of a year is $r_{0}$. Then the solvency ratio at the end of the year, $r$, is given by

$$
r=r_{0}(100+x) /(100+g)
$$

where $\quad x$ is the increase in shareholders' funds

and $\quad g$ is the increase in written premiums.

$r_{0}, r, x$ and $g$ are all percentages

Thus, given a fixed value of $r_{0}$, the position of the insurer at the end of the year can be depicted graphically by a point on one of the family of lines shown schematically in Figure 1. This family is obtained by plotting all possible pairs of values of $x$ and $r$. Each line passes through the point $(-100,0)$ and corresponds to a different value of $g$. The line given by $g=0$ passes through the point $\left(0, r_{0}\right)$. All lines corresponding to values of $g$ less than zero lie above this line (for values of $x$ greater than -100 ) and all lines corresponding to values of $g$ greater than zero lie below it.

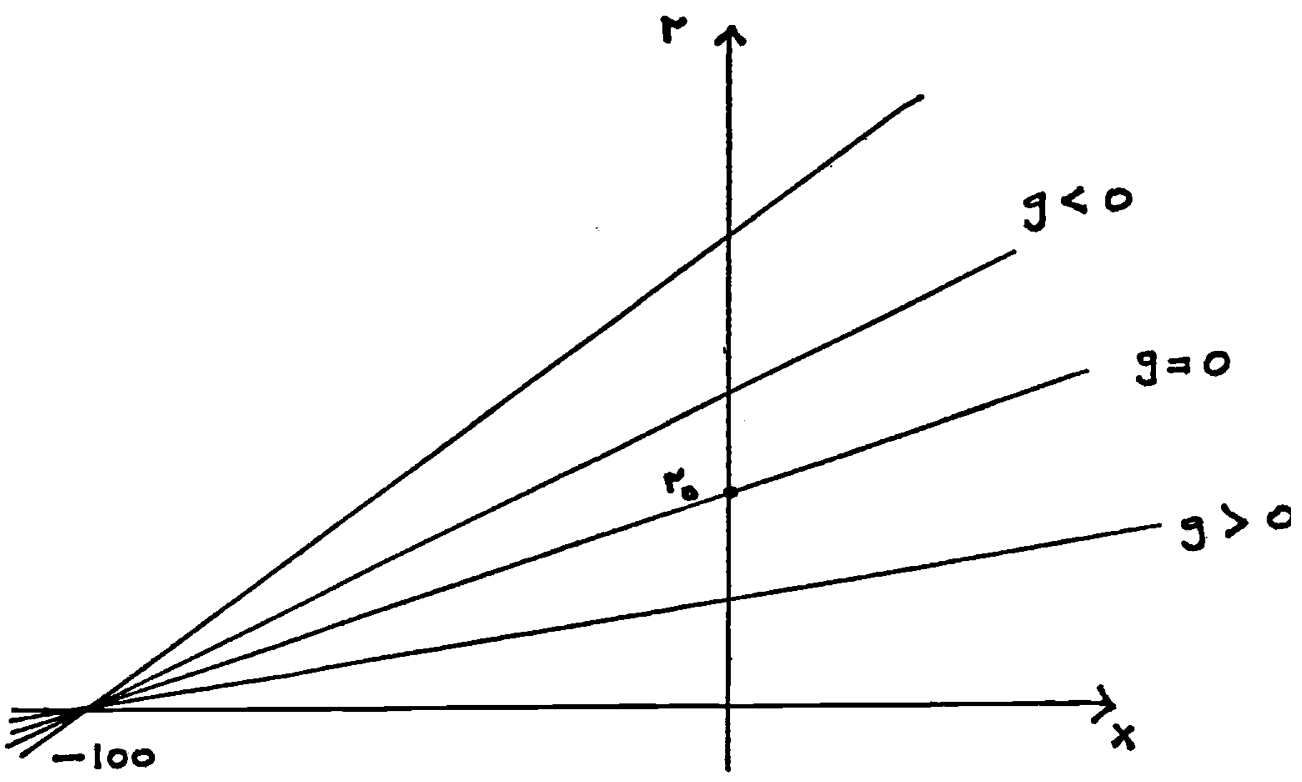

Figure 1 : Possible value of the increase in shareholders funds (x \%) and the solvency ratio at the end of the year ( $\mathrm{r} \%)$, given the initial solvency ratio $\mathrm{r}_{0}$.

The increase in premiums is $\mathrm{g} \%$

The actual line on which the point $(x, r)$ lies is determined by the value of $g$, which is itself determined by such factors as the increase in premiums rates, the increase in the number of policies, and the change in exchange rates. For a given value of $g$, the possible values of $x$ and $r$ are best regarded as probability distributions, because 
of the stochastic nature of the underwriting results. Moreover, different distributions on the same $g$ line correspond to different stategies adopted by the insurer. For example, the same growth in premiums may be obtained either by keeping the number of policies constant and increasing the premium rate, or by increasing the number of policies and keeping the premium rate constant. The latter strategy would probably result in a distribution of points on the $g$ line with significantly lower values of $x$ and $r$ than the distribution obtained from the first strategy. If the values of $x$ and $r$ take investment income into account, different investment stategies giving different returns on invested funds would likewise result in different distributions of $x, r$ values on the same $g$ line. This is shown schematically in Figure 2, the $x, r$ diagram for a given growth $g$ and two hypothetical strategies $X$ and $Y$. These have been depicted as distinct sets of $x, r$ values, for clarity, but in practice there might well be some overlap of the two distributions.

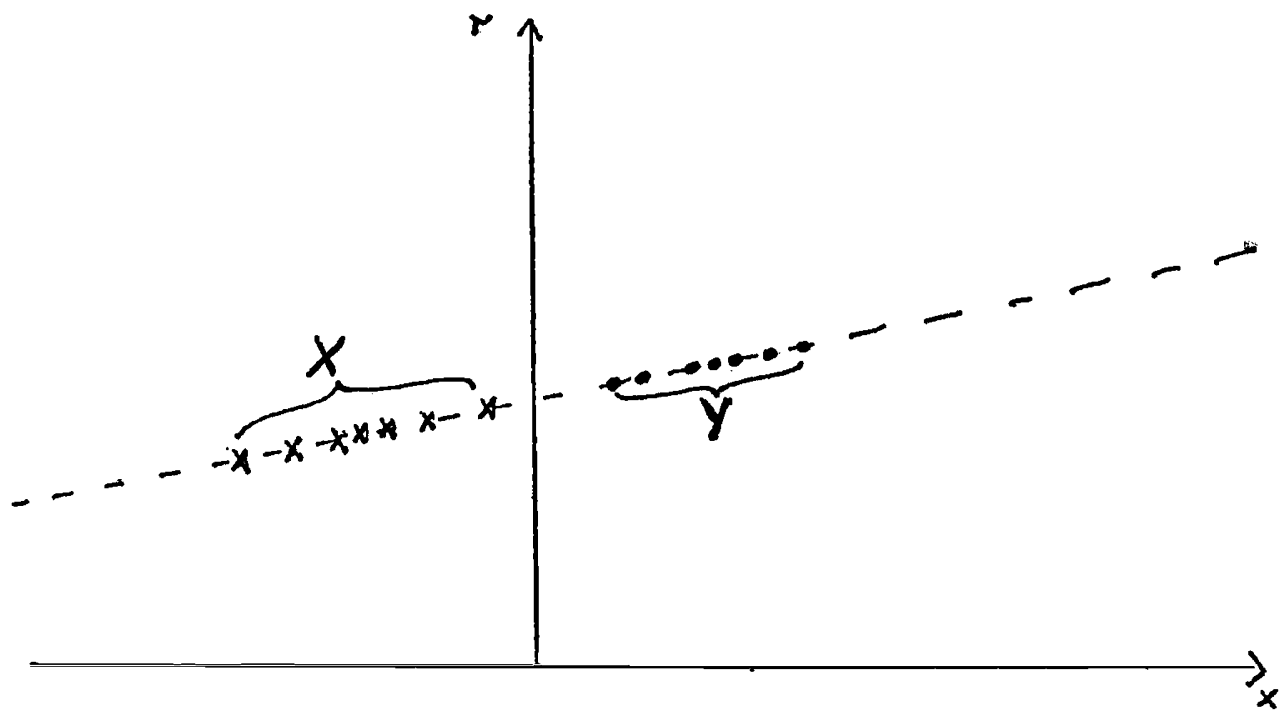

Figure 2 : Distributions of the possible $\mathrm{x}, \mathrm{r}$ values for two strategies $\mathrm{X}$ and $\mathrm{Y}$, given a fixed initial solvency ratio and a fixed growth of premiums.

This representation is completely general and may be used to describe any insurance business, either gross or net of reinsurance.

In order to focus on the effect of foreign exchange fluctuations, it is convenient to assume a fixed growth of premium income in terms of the actual currencies of payment. This value is denoted by $g_{F}$, and is the $g$ value giving the line in the $x, r$ diagram on which the results lie if exchange rates are constant.

If the insurer's home currency appreciates relative to the foreign currencies, then the $g$ value changes to some value $g_{A}$, where $g_{A}<g_{F}$, because the written premiums, converted at the end of year exchange rates, are less than the written premiums in 
the constant exchange rate situation. Conversely, if the insurer's home currency depreciates relative to the foreign currencies, the $g$ value becomes $g_{D}$, where $g_{D}>g_{F}$. This is shown in Figure 3.

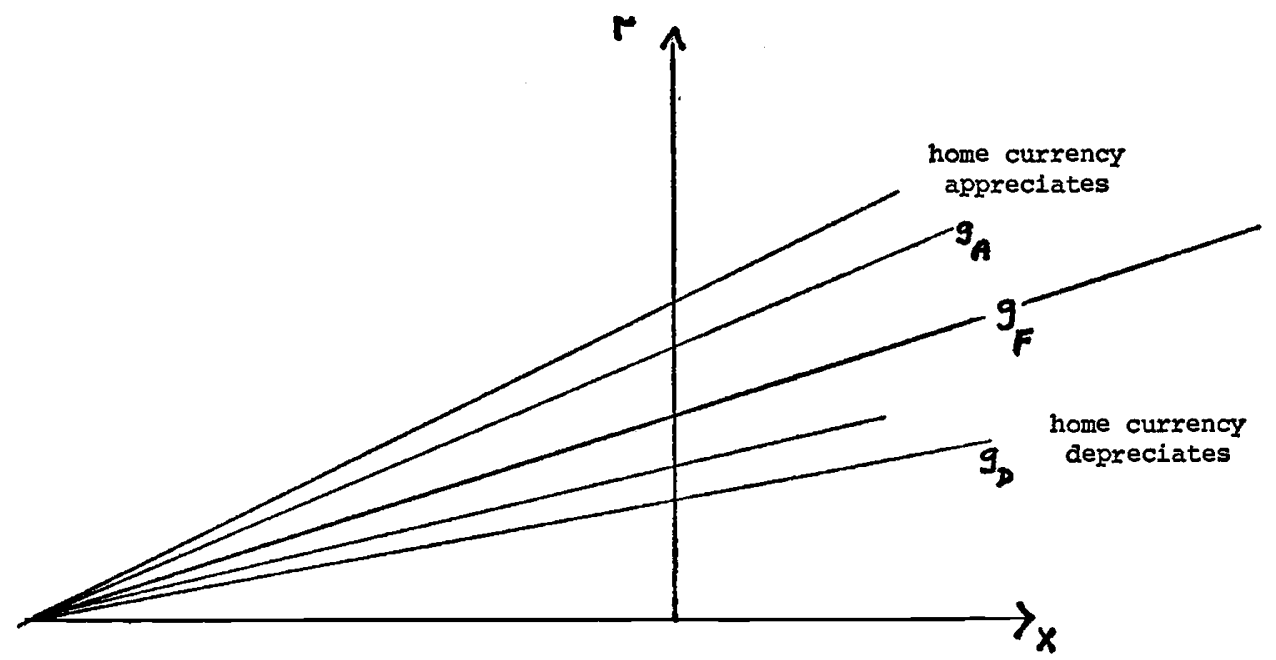

Figure 3 : Possible $\mathrm{x}, \mathrm{r}$ values, given the initial solvency ratio and the increase in premiums in the currencies of payment, $\mathrm{g}_{\mathrm{F}}$.

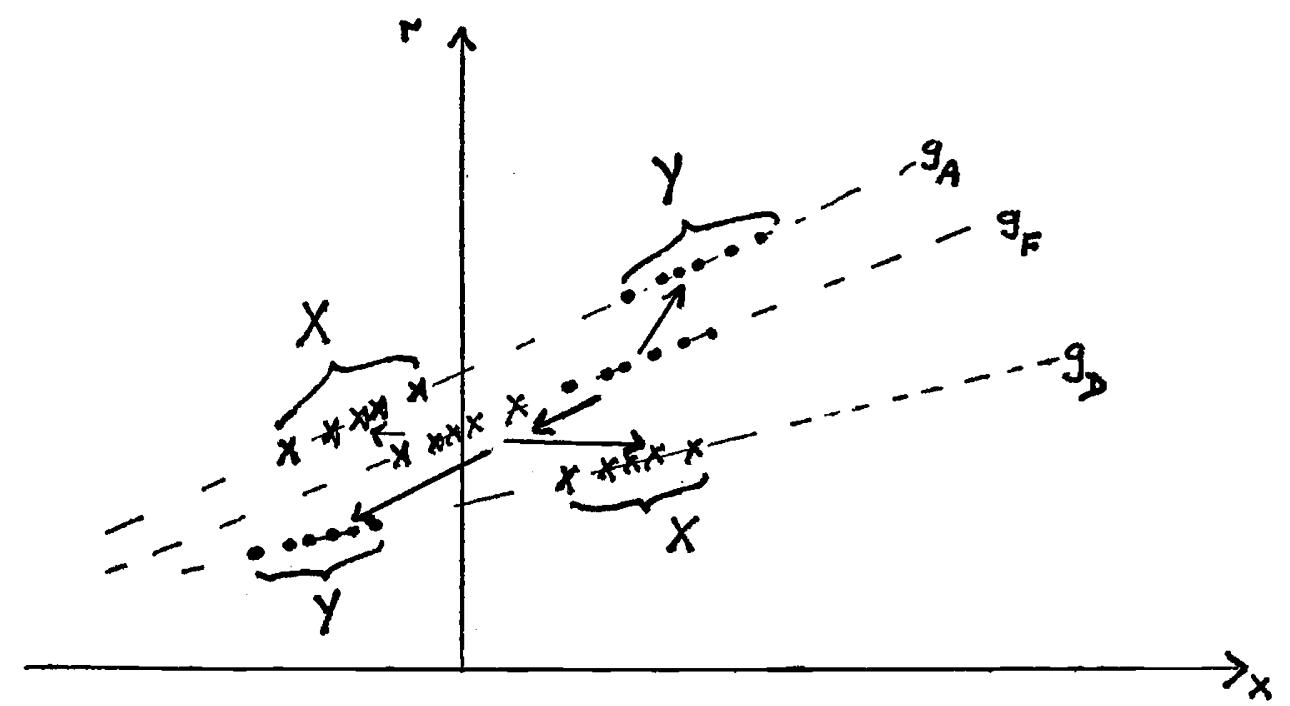

Figure 4 : Distributions of the possible $\mathrm{x}, \mathrm{r}$ values for two strategies $\mathrm{X}$ and $\mathrm{Y}$, given the initial solvency ratio and the growth of premiums under constant exchange rates, $\mathrm{g}_{\mathrm{F}}$. 
This gives rise to the typical $x, r$ diagram shown schematically in Figure 4, in which the distributions of the results of two hypothetical strategies, $X$ and $Y$, are depicted for the three cases of steady exchange rates, a fixed currency appreciation, and a fixed currency depreciation.

The exchange rate risk may be regarded as contributing an extra dimension to the probability distributions of the results, because of the shift from the $g_{F}$ line to a different $g$ line. In principle, if (subjective) probabilities could be assigned to exchange rate changes, it would be possible to calculate these bivariate probability distributions, for a given strategy and a given $g_{F}$. This study does not attempt to do this, but looks at different magnitudes and directions of exchange rate changes and demonstrates their effects on the results of different strategies.

A simple deterministic example of this kind of analysis was given by Lloyd [2]. He considered a U.K. company operating in sterling and dollars and three possible strategies :

$A$ all shareholders funds in U.K.

$B$ shareholders funds distributed in U.K. and abroad in proportion to premium income

C shareholders funds mainly in U.K.

Tables 1 and 2 are taken from Lloyd's paper. Table 1 shows the amounts of premium income and shareholders funds, in terms of sterling, under steady exchange

Table 1: Exchange rates constant

\begin{tabular}{|cccccccc|}
\hline \multirow{2}{*}{ STRATEGY } & \multicolumn{2}{c}{ PREMIUM INCOME } & \multicolumn{2}{c|}{ SHAREHOLDERS } & FUNDS & SOLVENCY \\
\cline { 2 - 8 } & U.K. & Overseas & Total & U.K. & Overseas & Total & MARGIN \\
\hline $\boldsymbol{A}$ & 20 & 80 & 100 & 60 & - & 60 & $60 \%$ \\
$B$ & 20 & 80 & 100 & 12 & 48 & 60 & $60 \%$ \\
$C$ & 20 & 80 & 100 & 40 & 20 & 60 & $60 \%$ \\
\hline
\end{tabular}

Table 2 : Sterling appreciates (depreciates)

\begin{tabular}{|ccccccccc|}
\hline \multirow{2}{*}{ STRATEGY } & \multicolumn{2}{c}{ PREMIUM INCOME } & \multicolumn{4}{c|}{ SHAREHOLDERS' } & FUNDS & SOLVENCY \\
\cline { 2 - 8 } & U.K. & Overseas & Total & U.K. & Overseas & Total & MARGIN \\
\hline$A$ & $20(20)$ & $60(100)$ & $80(120)$ & $60(60)$ & 0 & $(0)$ & $60(60)$ & $75 \%(50 \%)$ \\
$B$ & $20(20)$ & $60(100)$ & $80(120)$ & $12(12)$ & $36(60)$ & $48(72)$ & $60 \%(60 \%)$ \\
$C$ & $20(20)$ & $60(100)$ & $80(120)$ & $40(40)$ & $15(25)$ & $55(65)$ & $69 \%(54 \%)$ \\
\hline
\end{tabular}


rate conditions. It can be seen that, in the notation of this paper, $g_{F}=0$ and $r_{0}=60$. Only one possible point on the $g_{F}$ line is considered, with $x=0$ and $r=60$.

Table 2 shows the position after sterling appreciates or depreciates by $25 \%$ in terms of dollars, with the effects of depreciation shown by the figures in brackets. In the notation of this paper, $g_{A}=-20$ and $g_{D}=20$. The corresponding values of $x$ and $r$ are set out in Table 3.

Table 3: x,r values derived from Tables 1 and 2

\begin{tabular}{|cccc|}
\hline Strategy & $\begin{array}{c}\text { Constant } \\
\text { exchange } \\
\text { rate }: g=0\end{array}$ & $\begin{array}{c}\text { Sterling up } \\
25 \%: g=-20\end{array}$ & $\begin{array}{c}\text { Sterling down } \\
\mathbf{2 5 \%} \boldsymbol{g}=\mathbf{2 0}\end{array}$ \\
\hline$A$ & 0,60 & 0,75 & 0,50 \\
$B$ & 0,60 & $-20,60$ & 20,60 \\
$C$ & 0,60 & $-8.33,69$ & $8.33,54$ \\
\hline
\end{tabular}

This example is depicted graphically in Figure 5, with three points on each of the $g_{A}$ and $g_{D}$ lines, corresponding to the three strategies $A, B$ and $C$. It illustrates the fundamental trade-off between the two objectives, of maximising the solvency ratio and maximising the level of shareholders funds, which occurs in conditions of fluctuating exchange rates. Insurers operating either only in their home country, or in foreign countries with permanently fixed exchange rates, do not have this problem since maximising one automatically maximises the other. In Lloyd's example, an insurer whose main objective is to maintain the solvency ratio would choose strategy $B$, whereas an insurer whose main objective is to maintain the level of shareholders funds would choose strategy $\boldsymbol{A}$. Strategy $\boldsymbol{C}$ might be chosen by an insurer who gives roughly equal weight to each of these objectives. Of course, some of these strategies might not be available to the insurer because of statutory regulations imposed by either of the countries involved.

In the present study, the ASIR model was used to obtain estimates of the distributions of $x, r$ values, at the end of a year, which take into account investment income and taxation (taken as $50 \%$ of profits). One risk class and three possible strategies were investigated as follows :

$A$ all investments in the home country, $K h$

$B$ all investments in the country where the risks are taken, $K r$

$T$ technical reserves held in $K r$, shareholders funds in $K h$

The countries $K h$ and $K r$ were taken, in turn, to be two of the three hypothetical countries $K 1, K 2$ and $K 3$ in each of which interest and inflation rates were equal, at constant levels of $5 \%, 10 \%$ and $15 \%$ per year respectively. The eighteen combinations of countries and strategies are set out in Table 4. Each combination was simulated 
r Figure 5:A deterministic example of the $\mathrm{X}, \mathrm{r}$ values obtained under

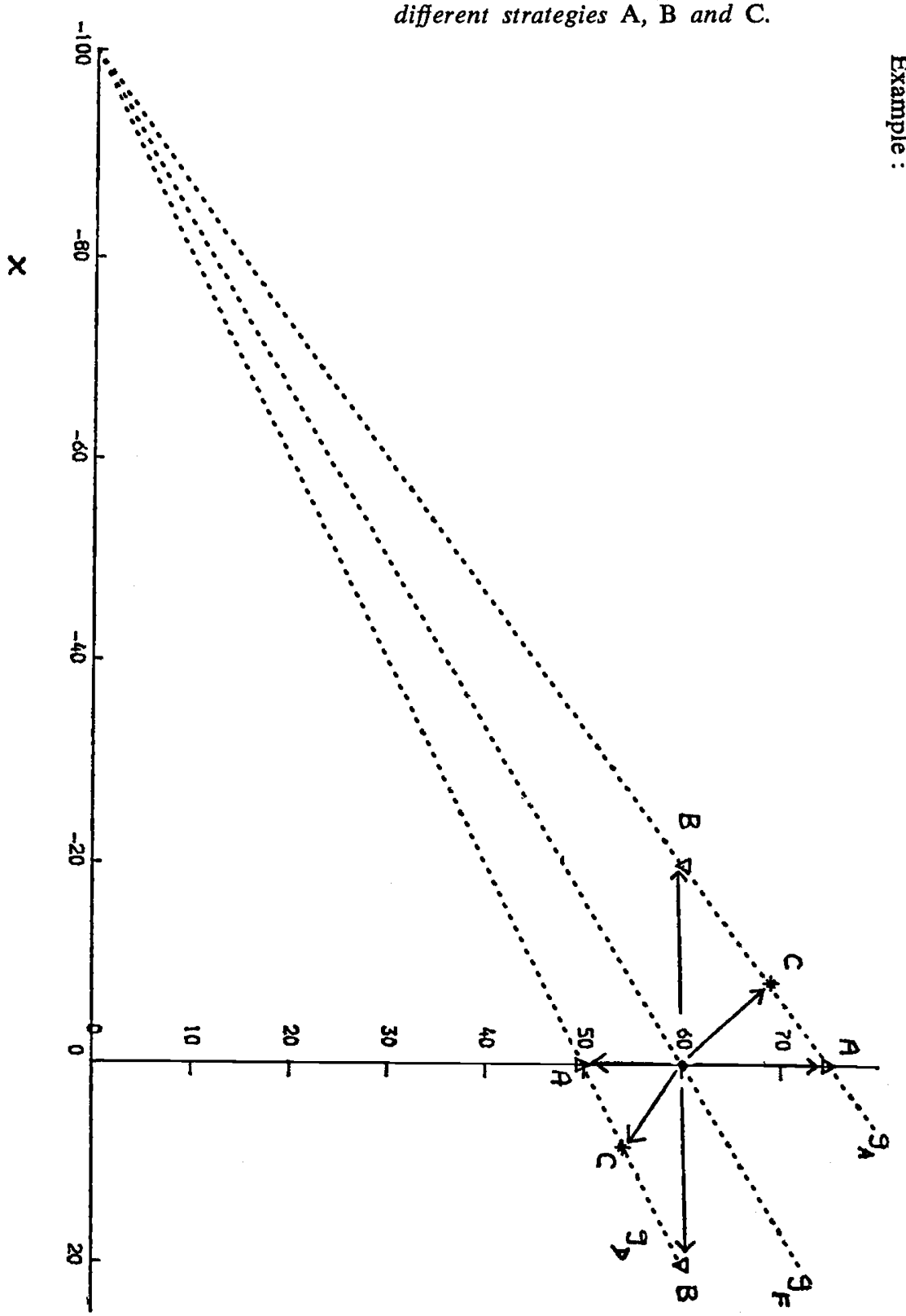


with one of the three different exchange rate changes in turn : steady exchange rates (no fluctuations), currency of $K h$ up by $10 \%$ at the end of the year relative to $K r$, and currency of $K r$ up by $10 \%$ at the end of the year relative to $K h$. An estimate of the $x, r$ distributions was obtained by running each simulated situation ten times with

Table 4 : Simulated combinations of countries and strategies

\begin{tabular}{|c|c|c|c|}
\hline$K h$ & $K r$ & Strategy & $K i$ \\
\hline$K 1$ & $K 2$ & $A$ & $K 1$ \\
\hline$K 1$ & $K 2$ & $B$ & $K 2$ \\
\hline$K 1$ & $K 2$ & $T$ & $K 1, K 2$ \\
\hline$K 1$ & $K 3$ & $\boldsymbol{A}$ & $K 1$ \\
\hline$K 1$ & $K 3$ & $\boldsymbol{B}$ & $K 3$ \\
\hline$K 1$ & $K 3$ & $T$ & $K 1, K 3$ \\
\hline$K 2$ & $K 1$ & $\boldsymbol{A}$ & $K 2$ \\
\hline$K 2$ & $K 1$ & $B$ & $K 1$ \\
\hline$K 2$ & $K 1$ & $T$ & $K 1, K 2$ \\
\hline$K 2$ & K3 & $A$ & $K 2$ \\
\hline$K 2$ & $K 3$ & $\boldsymbol{B}$ & $K 3$ \\
\hline$K 2$ & $K 3$ & $T$ & $K 2, K 3$ \\
\hline$K 3$ & $K 1$ & $A$ & $K 3$ \\
\hline K3 & $K 1$ & $B$ & $K 1$ \\
\hline$K 3$ & $K 1$ & $T$ & $K 3, K 1$ \\
\hline K3 & $K 2$ & $A$ & $K 3$ \\
\hline$K 3$ & $K 2$ & $B$ & $K 2$ \\
\hline$K 3$ & $K 2$ & $T$ & $K 3, K 2$ \\
\hline
\end{tabular}

$K h=$ country of registration of insurer

$K r=$ country where risks taken

$\boldsymbol{K} \boldsymbol{i}=$ country where investments held

Interest and inflation rates in $K 1=5 \%$ Interest and inflation rates in $K 2=10 \%$ Interest and inflation rates in $K 3=15 \%$ 
randomly generated random number seeds, making a total of 540 simulation runs for the 54 country / strategy / exchange rate combinations. More accurate estimates would of course be obtained by increasing the number of runs, but it was felt that sufficient indication of the gross differences between the strategies would be obtained for this study from ten.

A more detailed investigation was also made by carrying out a further 162 simulation runs, three for each of the 54 combinations, in which the same three random number seeds were used throughout. This meant that the same three basic sets of claims (at initial prices) were generated for each combination so that the differences between the results generated from the same random number seed were entirely due to different strategies and environments and not to stochastic variations in the risks themselves.

The parameters for the simulated risk class were derived from the claims settlement analysis data of a Property Risk Class (Risk Group Fire) written in the U.S.A. by a U.K. insurer. This was chosen because a number of U.K. insurers underwrite property risks in foreign countries, and the data seemed to exhibit the typical characteristics of such a risk class, notably the relatively small maximum time between incurrence and settlement (four years) and the very high proportion of small claims settled within three months of incurrence. This data and the claims parameters derived from it are in the appendix.

The number of policies was assumed to remain constant. It was also necessary to make some assumptions about premium rates. They were assumed to increase with inflation each year, and the initial level was calculated as the rate which gave an expected zero underwriting profit. Since the constant inflation rates in $K 1, K 2$ and $K 3$ were $5 \%, 10 \%$ and $15 \%$ respectively, this meant that premiums were greatest for the risk class in $K 3$, and least for the risk class in $K 1$, because the underwriting profit takes into account the expected increase in outstanding claims due to inflation.

The initial solvency ratio was taken to be $20 \%$ in each case, and the initial level of technical reserves was calculated as $40 \%$ of the previous years premiums plus the expected outstanding claims (based on the average claim settlement pattern). The initial level of investments was then calculated as the sum of the shareholders funds (equal to $20 \%$ of the previous years premiums) and the initial technical reserves less the net current assets, the latter comprising premiums accounted for but not yet received less commissions (ditto). As described above, all investments were held in one country under strategies $A$ and $B$; under strategy $T$ the shareholders funds were invested in the home country, and the remainder in the country where the risks were taken.

Under these assumptions, the effect of different inflationary environments on the amount of funds invested is shown in Table 5, where all amounts have been expressed in terms of the initial level of shareholders funds (taken as 100) when the risk class is in $K 1$. The amount of funds invested turns out to be approximately equal to the premiums written during year 0 , and the funds invested for the case $K r=K 3$ are only $6 \%$ greater than the funds invested when $K r=K 1$. A risk class with a larger claims settlement " tail", such as a Liability Class, would have had proportionately more funds invested in the higher inflationary environments. 
Table 5 : Balance sheet levels for the same risk class

in different inflationary environments

\begin{tabular}{|ccccc|}
\hline \multicolumn{5}{|c|}{ Amounts at beginning of year 1 } \\
\hline$K r$ & $\begin{array}{c}\text { Shareholders } \\
\text { Funds }\end{array}$ & $\begin{array}{c}\text { Technical } \\
\text { Reserves }\end{array}$ & $\begin{array}{c}\text { Total } \\
\text { Investments }\end{array}$ & $\begin{array}{c}\text { Premiums } \\
\text { Year 0 }\end{array}$ \\
\hline$K 1$ & 100.0 & 423.3 & 496.4 & 500.0 \\
$K 2$ & 102.5 & 436.0 & 511.0 & 512.5 \\
$K 3$ & 105.1 & 449.1 & 525.9 & 525.5 \\
\hline
\end{tabular}

$K r=$ country where risks are taken

Currency of premiums $=$ currency of $\boldsymbol{K r}$

All investments were assumed to be in one year term, fixed interest bonds, the return on investment being equal to the interest rate (and hence the inflation rate) prevailing in the country where invested. Thus if exchange rates remain constant, an insurer would obtain maximum investment income by holding all funds in $K 3$. This is illustrated in Figure 6 which shows the distribution of $x, r$ values (including investment income and after taxation of profits) at the end of year 1 for the same property risks underwritten in countries $K 1, K 2$ and $K 3$, and for the three different stategies of holding all investments in $K 1, K 2$ or $K 3$. The three lines on which the distributions lie have $g$ values of 5,10 and 15 respectively ; this follows directly from the assumptions of a constant number of policies and an increase in premiums equal to inflation.

Although there is some overlap, in general there are three distinct distributions of points along each $g$ line corresponding to the three different interest rates. Figure 6 also shows that, given the same country of investment, solvency ratios are greatest for the risk class in $K 1$ and least for the risk class in $K 3$, on average. This is because the investment income from the relatively small extra amount of funds invested is not sufficient to compensate for the greater increase in shareholders funds required to raise the solvency ratio in higher inflationary environments. Another feature is the small scatter of points for the case when investments and risk class are both in $K 3$, compared with the much greater spreads in other cases. This illustrates the increasing dominance of investment income as interest and inflation rates rise; the random nature of the underwriting results is swamped by it, while at lower levels of interest or inflation, the importance of the underwriting results is shown by the much wider spread of $x, r$ values along the $g$ lines.

The results shown in Figure 6 and summarised in Table 6 are in fact the steady exchange rate cases of strategies $A$ and $B$, defined previously, for the combinations of countries listed in Table 4. (The apparent discrepancy in numbers - 9 cases shown in Figure 6 and Table 6 as compared with 12 listed in Table $4-$ is because the results 
Solvency ratio at end of year \%

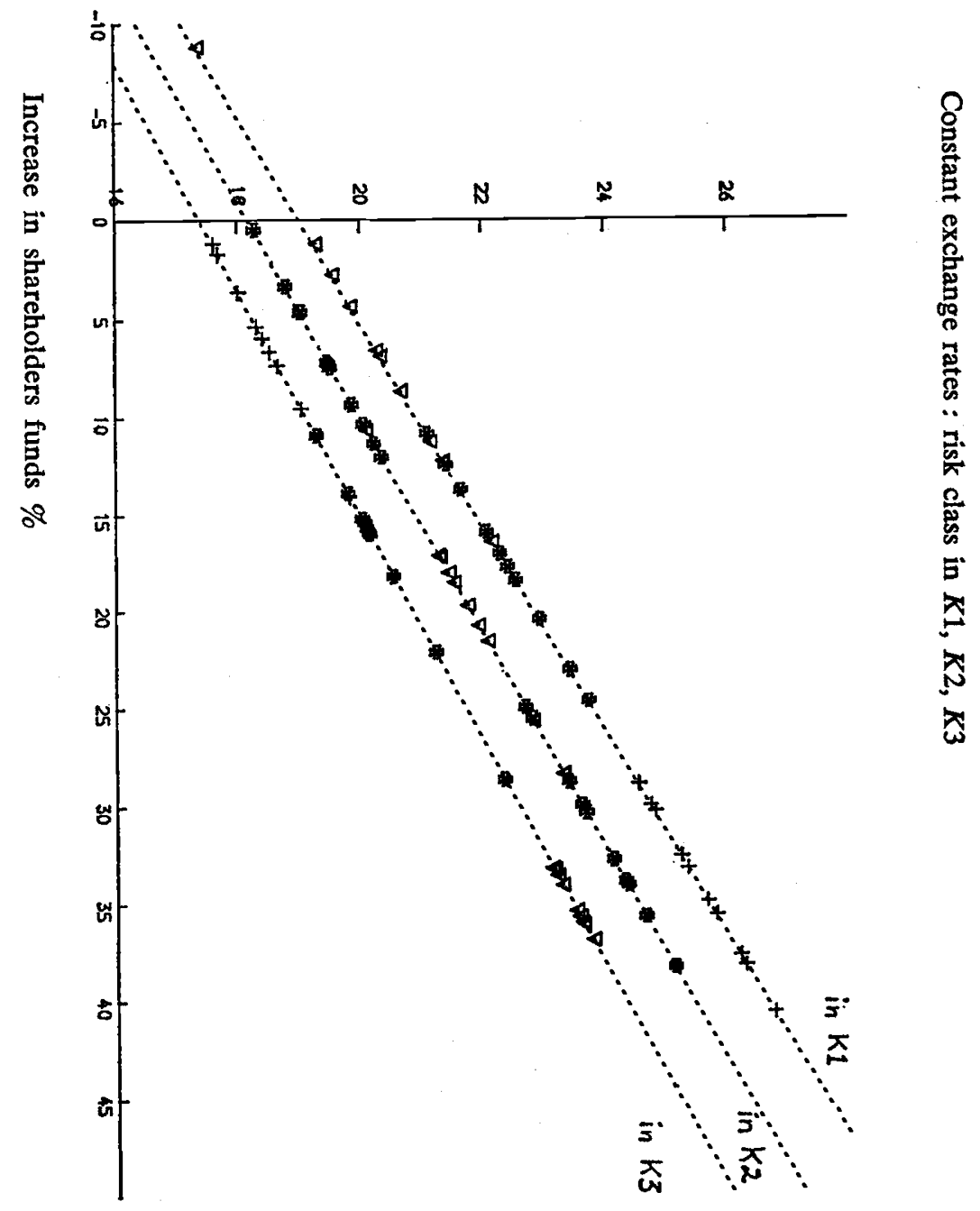

Figure 6: Results are classified according to investment strategy : $\nabla=$ investments in same country as risk class 结 $=$ investments in country with $\pm 5 \%$ differential in rates $+=$ investments in country with $\pm 10 \%$ differential in rates 
of three of the $B$ cases are duplicated in the steady exchange rate situation.) They are compared with the results obtained in fluctuating exchange rates in the following section.

Table 6:Values of the mean and range of the increase in shareholders funds and the solvency ratio at the end of the year, estimated from sets of ten simulation runs at constant exchange rates

\begin{tabular}{|c|c|c|c|c|c|}
\hline \multicolumn{2}{|c|}{ Country } & \multicolumn{2}{|c|}{$\begin{array}{c}\text { Increase in shareholders funds } \\
\%\end{array}$} & \multicolumn{2}{|c|}{$\begin{array}{c}\text { Solvency ratio at end of year } \\
\%\end{array}$} \\
\hline Risk Class & Investments & Mean & (Range) & Mean & (Range) \\
\hline \multirow{3}{*}{$K 1$} & $K 1$ & 6.1 & $(-8.8,16.4)$ & 20.2 & $(17.4,22.2)$ \\
\hline & $K 2$ & 17.4 & $(10.8,24.6)$ & 22.4 & $(21.1,23.7)$ \\
\hline & $K 3$ & 34.1 & $(28.8,40.5)$ & 25.5 & $(24.5,26.8)$ \\
\hline \multirow{3}{*}{$K 2$} & $K 1$ & 7.3 & $(0.5,12.0)$ & 19.5 & $(18.3,20.4)$ \\
\hline & $K 2$ & 19.7 & $(10.6,28.3)$ & 21.8 & $(20.1,23.3)$ \\
\hline & $K 3$ & 31.4 & $(24.9,38.2)$ & 23.9 & $(22.7,25.1)$ \\
\hline \multirow{3}{*}{$K 3$} & $K 1$ & 6.9 & $(1.2,14.1)$ & 18.6 & $(17.6,19.8)$ \\
\hline & $K 2$ & 17.2 & $(10.9,28.6)$ & 20.4 & $(19.3,22.4)$ \\
\hline & K3 & 34.7 & $(33.2,36.8)$ & 23.4 & $(23.2,23.8)$ \\
\hline
\end{tabular}

\section{Results}

As explained in Section 2, six basic combinations of countries were simulated ; the insurer was based in one of the three hypothetical countries $K 1, K 2$ or $K 3$ (the home country $K h$ ) and the risk were underwritten in one of the remaining two countries (the foreign country $K r$ ). The results are depicted graphically in two sets of diagrams, Figures 7 to 12 and Figures 13 to 18.

Figures 7 to 12 show, for each basic country combination in turn, the 90 randomly generated results obtained from ten simulation runs of each combination of strategy and exchange rate environment. These graphs are intended to give an idea of the distributions of the results. The average values of the increase in shareholders funds (the $x$ values) and the solvency ratio at the end of the year (the $r$ values) calculated from these samples are given in Tables 7 and 8 respectively.

Figures 13 to 18 show, again for each basic country combination in turn, the 27 results generated by three random number seeds. These seeds will be referred to as seed 1 , seed 2 and seed 3 respectively although their actual numerical values, which 
Table 7 : Expected values of the percentage increase in shareholders funds at the end of the year calculated as the mean of ten simulation runs

\begin{tabular}{|c|c|c|c|c|c|c|c|c|c|c|}
\hline \multicolumn{2}{|c|}{ Country } & \multicolumn{9}{|c|}{ Strategy } \\
\hline Insurer & $\begin{array}{l}\text { Risk } \\
\text { Class }\end{array}$ & & $A$ & & & $B$ & & & $T$ & \\
\hline \multirow{2}{*}{$K 1$} & $K 2$ & 41.1 & 7.3 & -42.5 & 8.8 & 19.7 & 31.6 & 14.9 & 15.2 & 13.8 \\
\hline & $K 3$ & 40.2 & 6.9 & -43.9 & 22.4 & 34.7 & 48.1 & 24.0 & 21.8 & 24.9 \\
\hline \multirow{2}{*}{$K 2$} & $K 3$ & 55.3 & 17.2 & -25.7 & 22.4 & 34.7 & 48.1 & 25.5 & 24.7 & 27.9 \\
\hline & $K 1$ & 56.3 & 17.4 & -22.7 & -3.5 & 6.1 & 16.7 & 7.2 & 8.4 & 5.7 \\
\hline \multirow{2}{*}{$K 3$} & $K 1$ & 70.2 & 34.1 & -6.6 & -3.5 & 6.1 & 16.7 & 11.1 & 8.8 & 11.5 \\
\hline & $K 2$ & 72.0 & 31.4 & -9.8 & 8.8 & 19.7 & 31.7 & 19.1 & 20.2 & 17.7 \\
\hline & & $\begin{array}{l}\text { home } \\
\text { currency } \\
\text { up } 10 \%\end{array}$ & & $\begin{array}{l}\text { foreign } \\
\text { currency } \\
\text { up } 10 \%\end{array}$ & $\begin{array}{c}\text { home } \\
\text { currency } \\
\text { up } 10 \%\end{array}$ & & $\begin{array}{l}\text { foreign } \\
\text { currency } \\
\text { up } 10 \%\end{array}$ & $\begin{array}{l}\text { home } \\
\text { currency } \\
\text { up } 10 \%\end{array}$ & & $\begin{array}{l}\text { foreign } \\
\text { currency } \\
\text { up } 10 \%\end{array}$ \\
\hline
\end{tabular}

Table 8: Expected values of the solvency ratio at the end of the year calculated as the mean of ten simulation runs

\begin{tabular}{|c|c|c|c|c|c|c|c|c|c|c|}
\hline \multicolumn{2}{|c|}{ Country } & \multicolumn{9}{|c|}{ Strategy } \\
\hline Insurer & $\begin{array}{l}\text { Risk } \\
\text { class }\end{array}$ & & $A$ & & & $B$ & & & $T$ & \\
\hline \multirow{2}{*}{$K 1$} & $K 2$ & 27.6 & 19.5 & 9.5 & 21.8 & 21.8 & 21.8 & 23.0 & 20.9 & 18.8 \\
\hline & $K 3$ & 26.8 & 18.6 & 8.9 & 23.4 & 23.4 & 23.4 & 23.7 & 21.2 & 19.7 \\
\hline \multirow{2}{*}{ K2 } & $K 3$ & 29.7 & 20.4 & 11.7 & 23.4 & 23.4 & 23.4 & 24.0 & 21.7 & 20.2 \\
\hline & $K 1$ & 32.8 & 22.4 & 13.4 & 20.2 & 20.2 & 20.2 & 22.5 & 20.9 & 18.3 \\
\hline \multirow{2}{*}{$K 3$} & $\boldsymbol{K} 1$ & 35.7 & 25.5 & 16.2 & 20.2 & 20.2 & 20.2 & 23.3 & 20.7 & 19.3 \\
\hline & $K 2$ & 34.4 & 23.9 & 14.9 & 21.8 & 21.8 & 21.8 & 23.8 & 21.9 & 19.5 \\
\hline & & $\begin{array}{l}\text { home } \\
\text { currency } \\
\text { up } 10 \%\end{array}$ & & $\begin{array}{l}\text { foreign } \\
\text { currency } \\
\text { up } 10 \%\end{array}$ & $\begin{array}{l}\text { home } \\
\text { currency } \\
\text { up } 10 \%\end{array}$ & & $\begin{array}{l}\text { foreign } \\
\text { currency } \\
\text { up } 10 \%\end{array}$ & $\begin{array}{l}\text { home } \\
\text { currency } \\
\text { up } 10 \%\end{array}$ & & $\begin{array}{l}\text { foreign } \\
\text { currency } \\
\text { up } 10 \%\end{array}$ \\
\hline
\end{tabular}




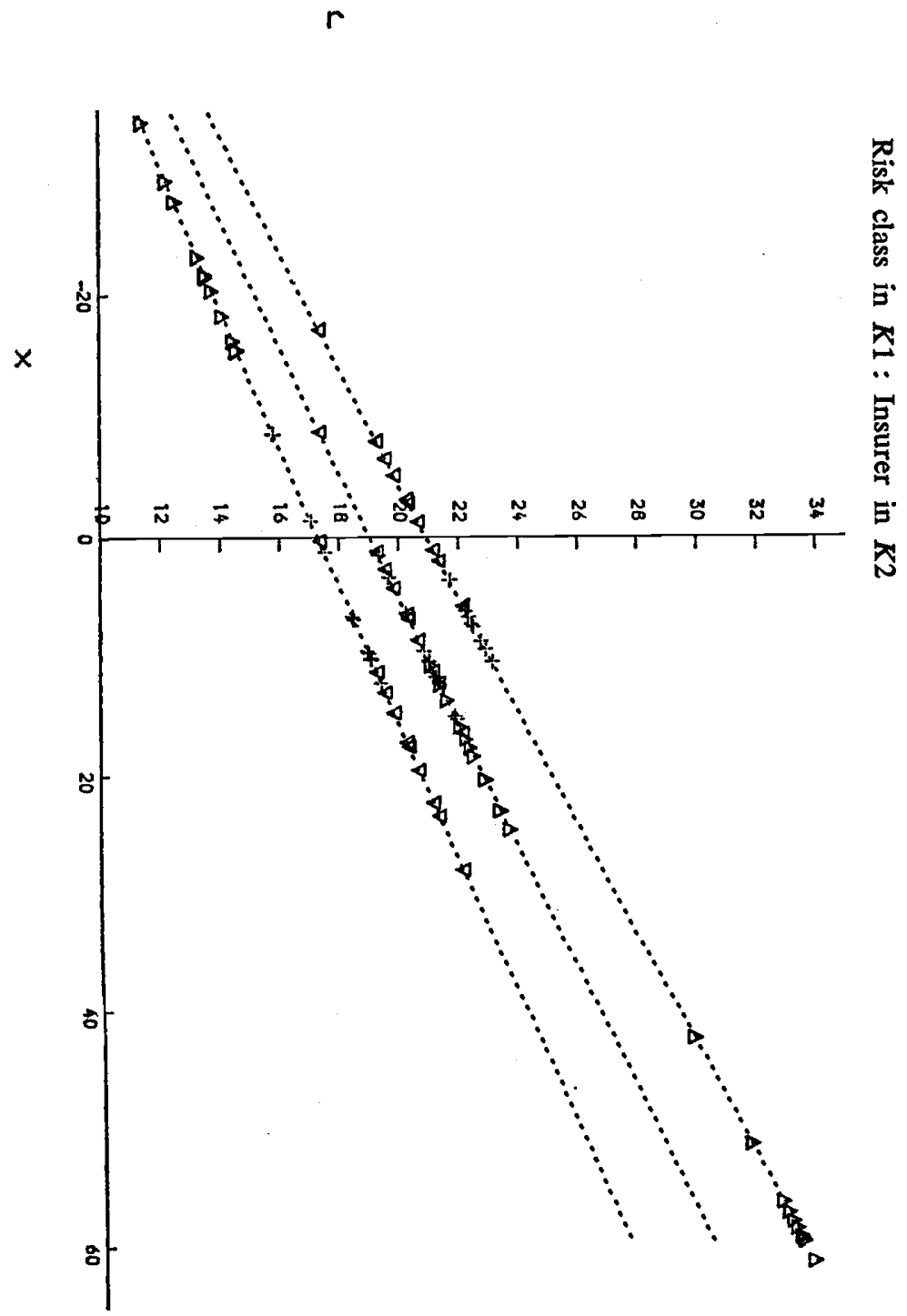

Figure 7 : Random samples :

$\triangle$ denotes results of strategy $\mathrm{A}$

$\nabla$ denotes results of strategy B

+ denotes results of strategy $\mathrm{T}$

Top line: home currency appreciates by $10 \%$

Bottom line: foreign currency appreciates by $10 \%$ 


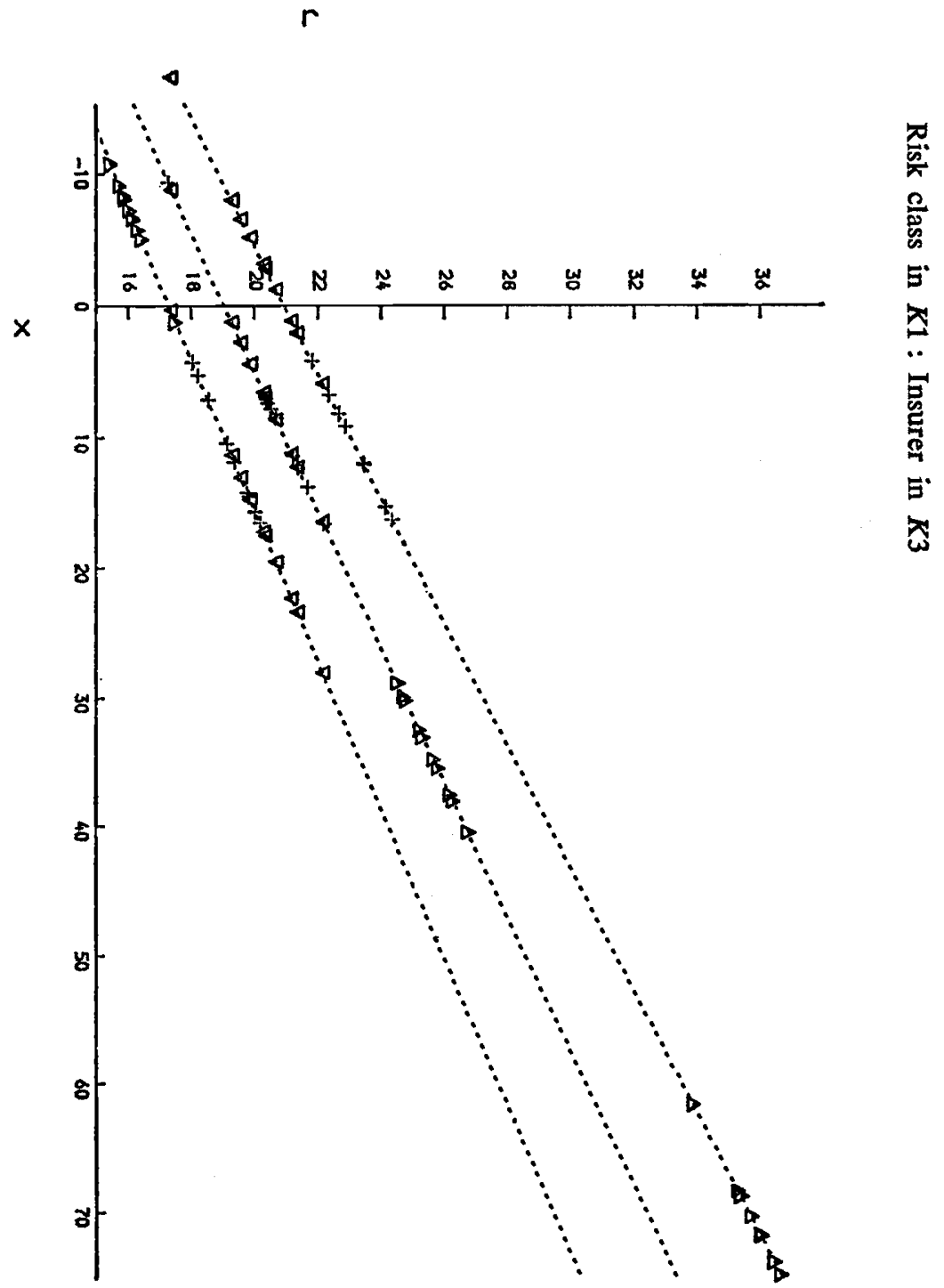

Figure 8: Random samples:

$\triangle$ denotes results of strategy $\mathbf{A}$

$\nabla$ denotes results of strategy B

+ denotes results of strategy $\mathrm{T}$

Top line: home currency appreciates by $10 \%$

Bottom line: foreign currency appreciates by $10 \%$ 


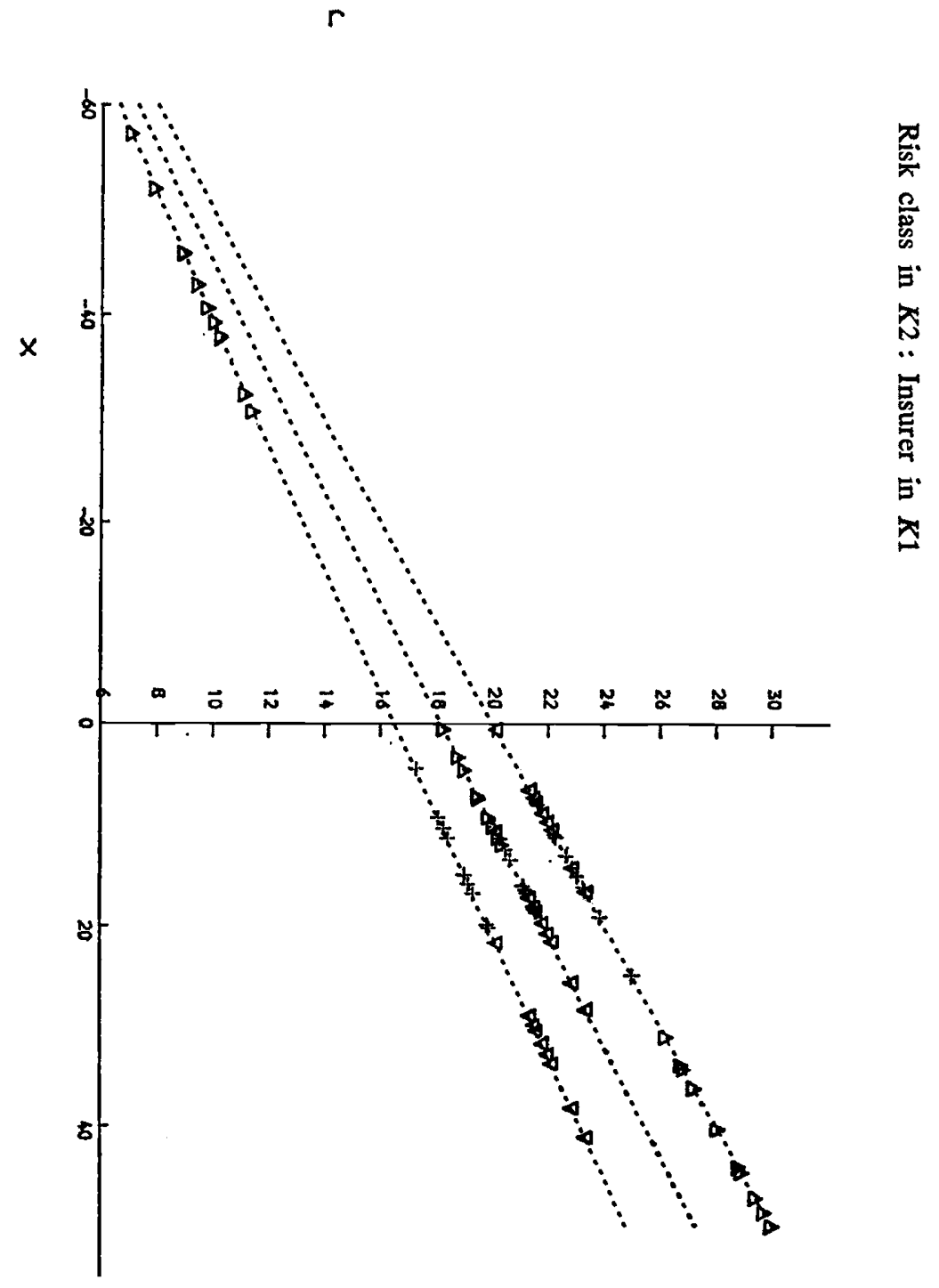

Figure 9: Random samples:

$\triangle$ denotes results of strategy $\mathrm{A}$

$\nabla$ denotes results of strategy $\mathbf{B}$

+ denotes results of strategy $\mathrm{T}$

Top line: home currency appreciates by $10 \%$

Bottom line: foreign currency appreciates by $10 \%$ 


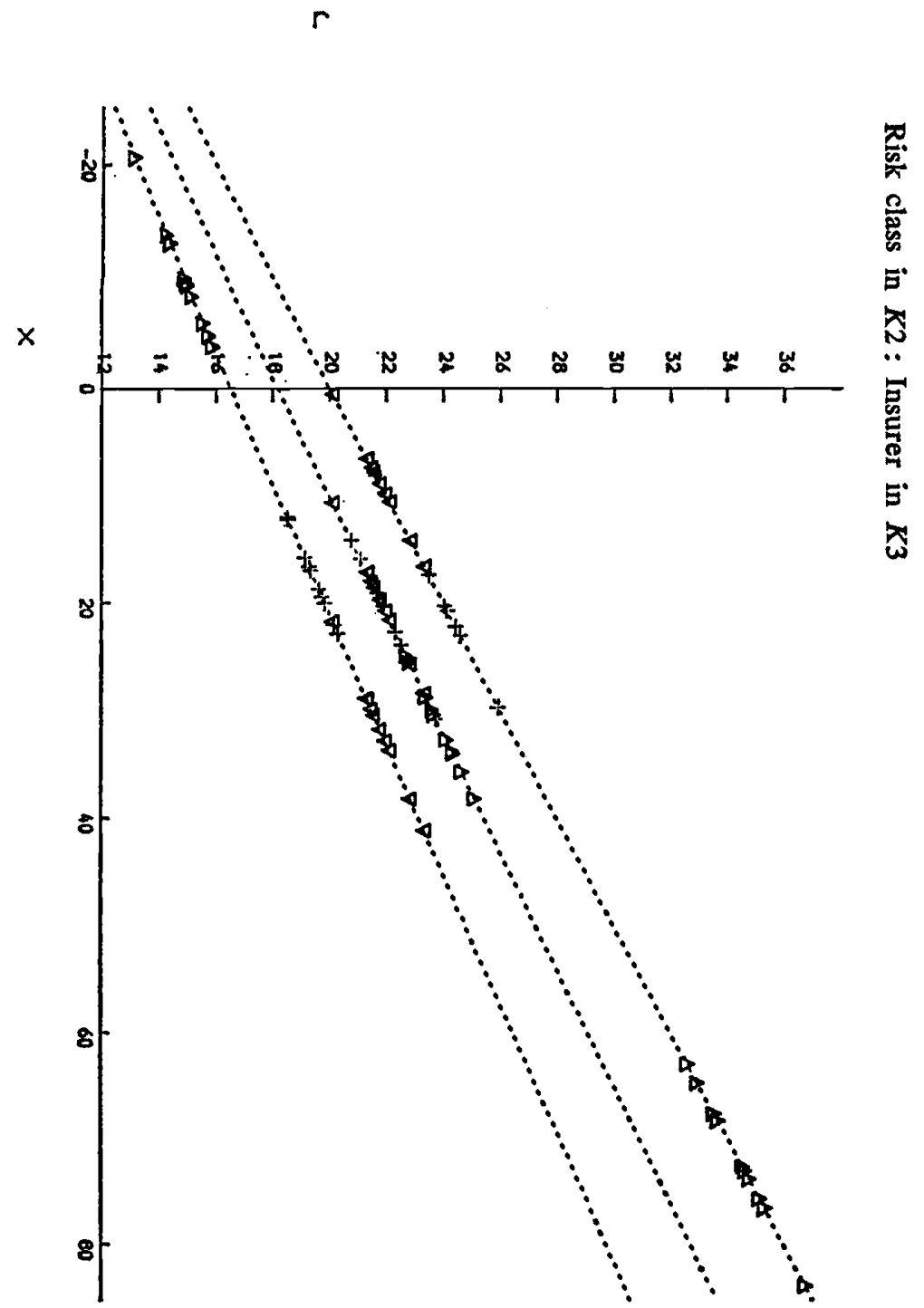

Figure 10: Random samples:

$\Delta$ denotes results of strategy $A$

$\nabla$ denotes results of strategy $\mathrm{B}$

+ denotes results of strategy $\mathrm{T}$

Top line: home currency appreciates by $10 \%$

Bottom line: foreign currency appreciates by $10 \%$ 
$r$

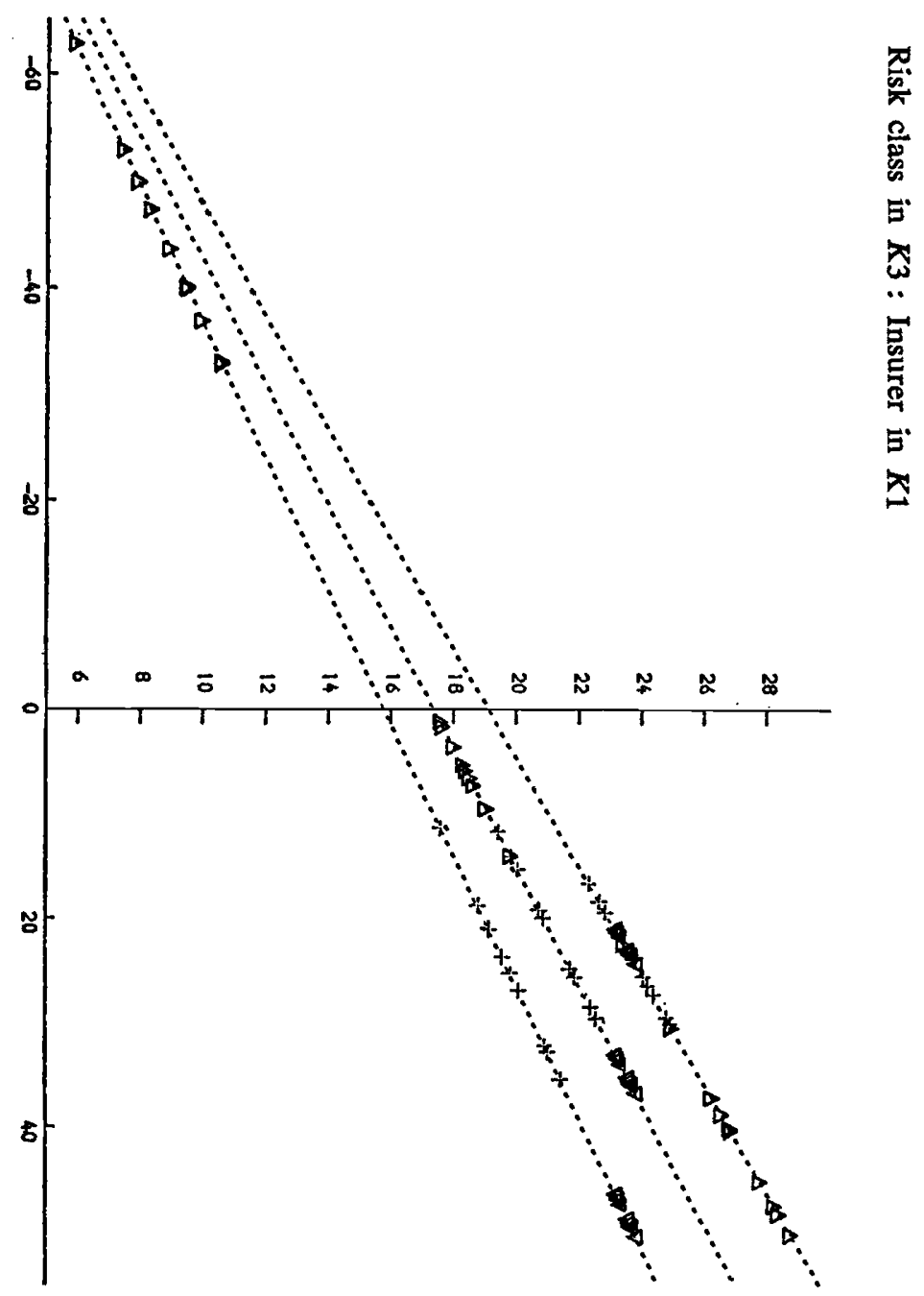

Figure $11:$ Random samples:

$\Delta$ denotes results of strategy $A$

$\nabla$ denotes results of strategy $\mathrm{B}$

+ denotes results of strategy $\mathrm{T}$

Top line: home currency appreciates by $10 \%$

Bottom line: foreign currency appreciates by $10 \%$ 


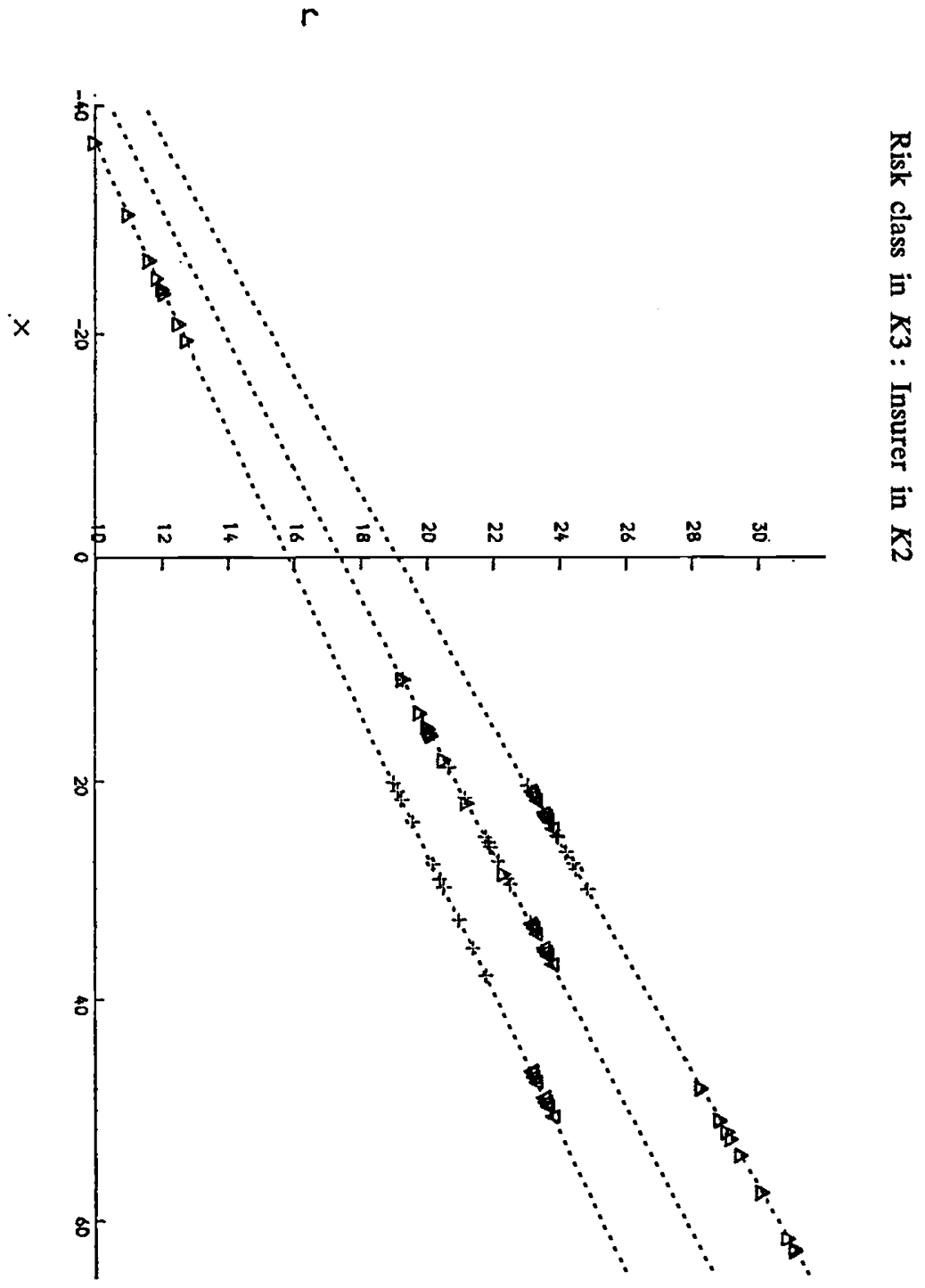

Figure 12 : Random samples:

$\Delta$ denotes results of strategy. A

$\nabla$ denotes results of strategy $\mathrm{B}$

+ denotes results of strategy $\mathrm{T}$

Top line: home currency appreciates by $10 \%$

Bottom line: foreign currency appreciates by $10 \%$ 


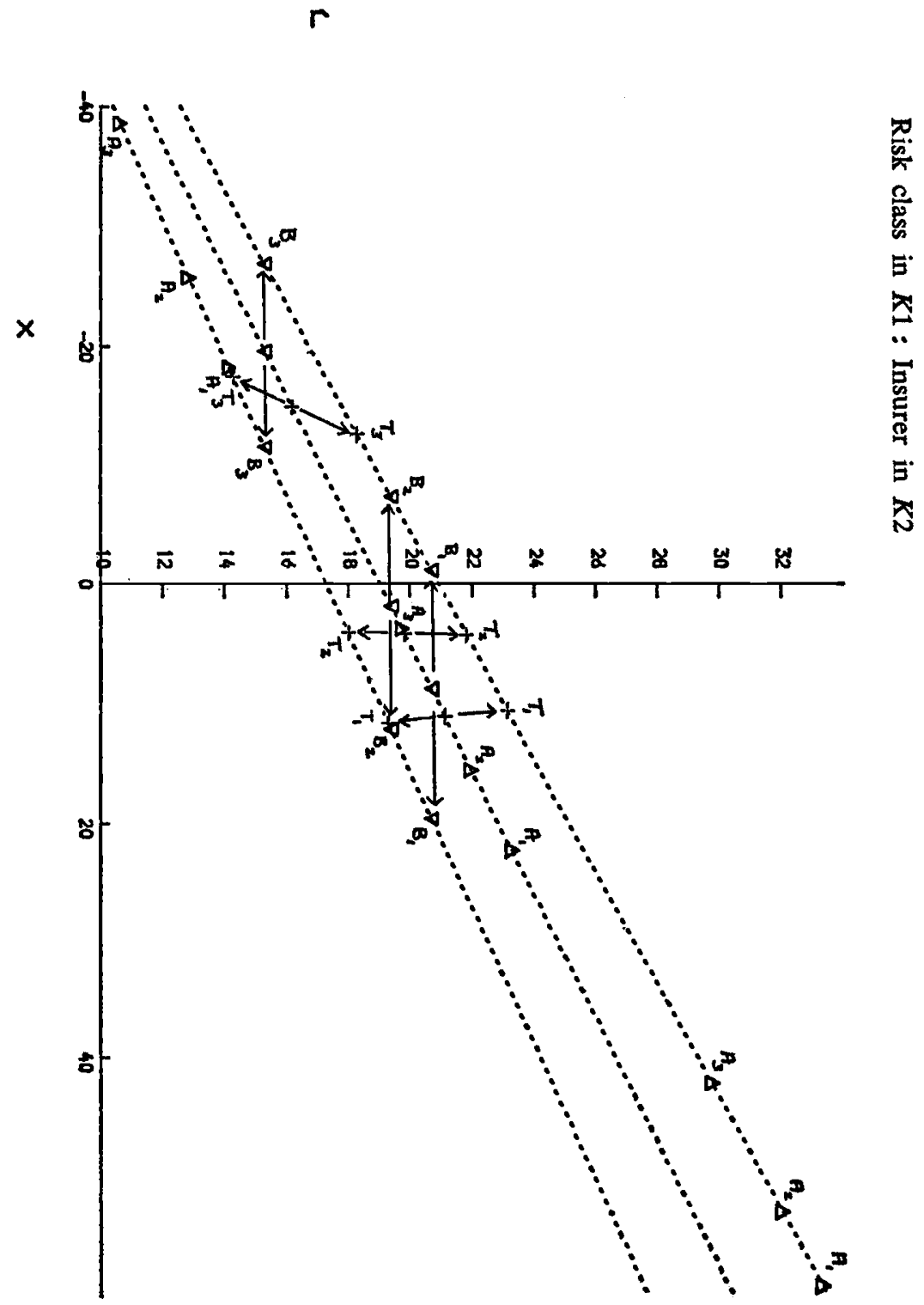

Figure 13 : Results generated by three random number seeds and three different strategies.

Top line: home currency appreciates by $10 \%$ Bottom line: foreign currency appreciates by $10 \%$ 


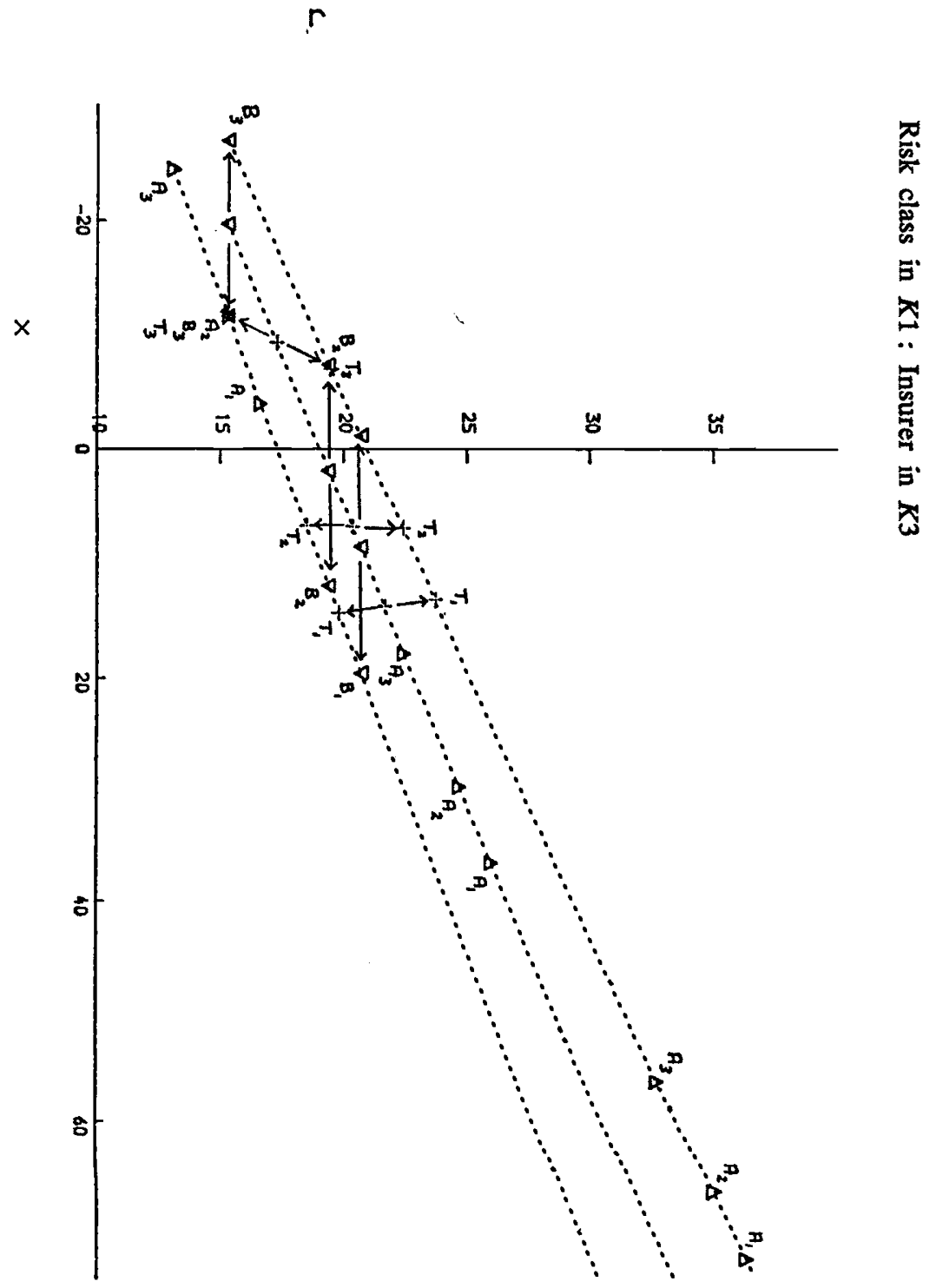

Figure $14:$ Results generated by three random number seeds and three different strategies.

Top line: home currency appreciates by $10 \%$

Bottom line: foreign currency appreciates by $10 \%$ 


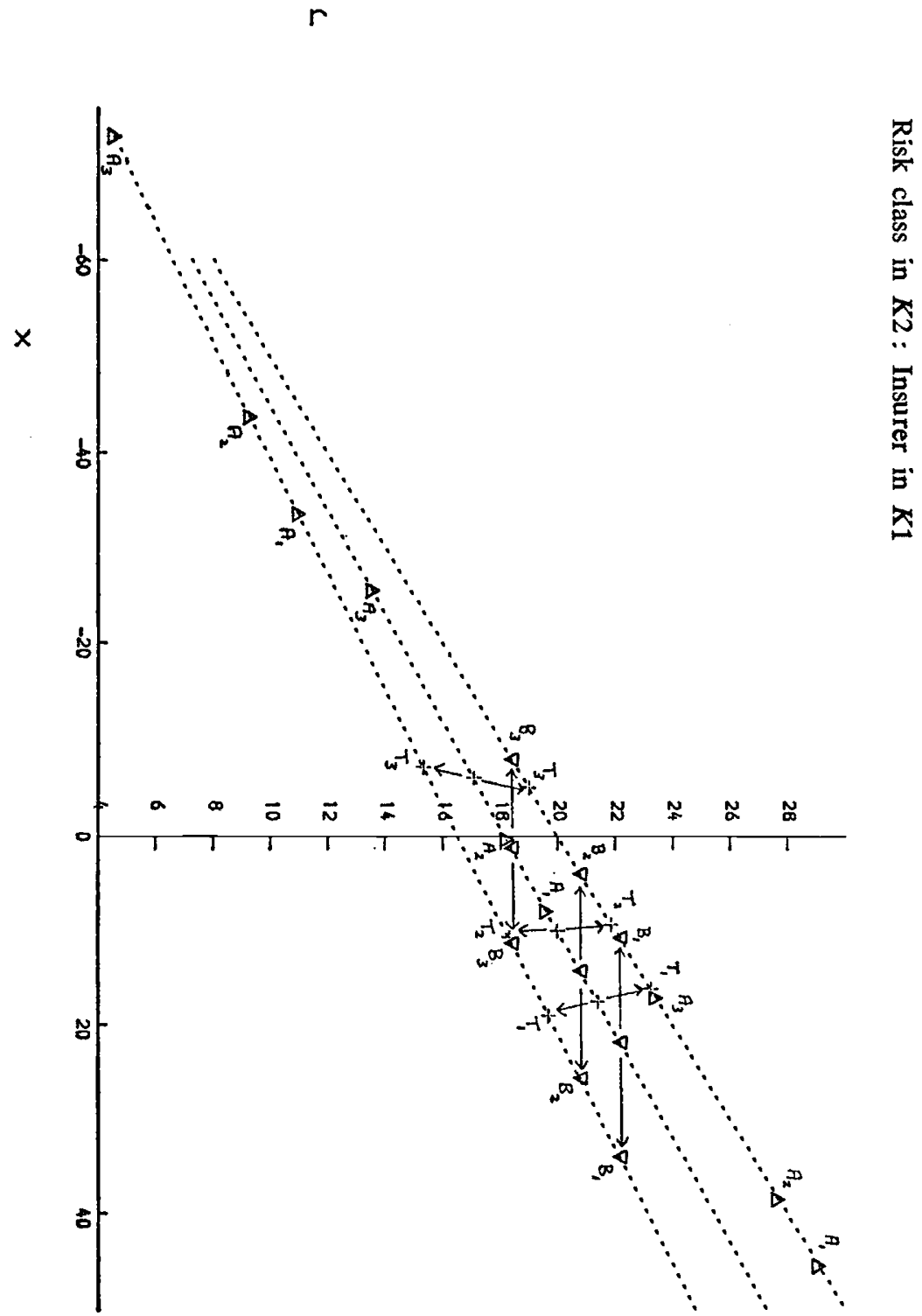

Figure $15:$ Results generated by three random number seeds and three different strategies.

Top line: home currency appreciates by $10 \%$

Bottom line: foreign currency appreciates by $10 \%$ 


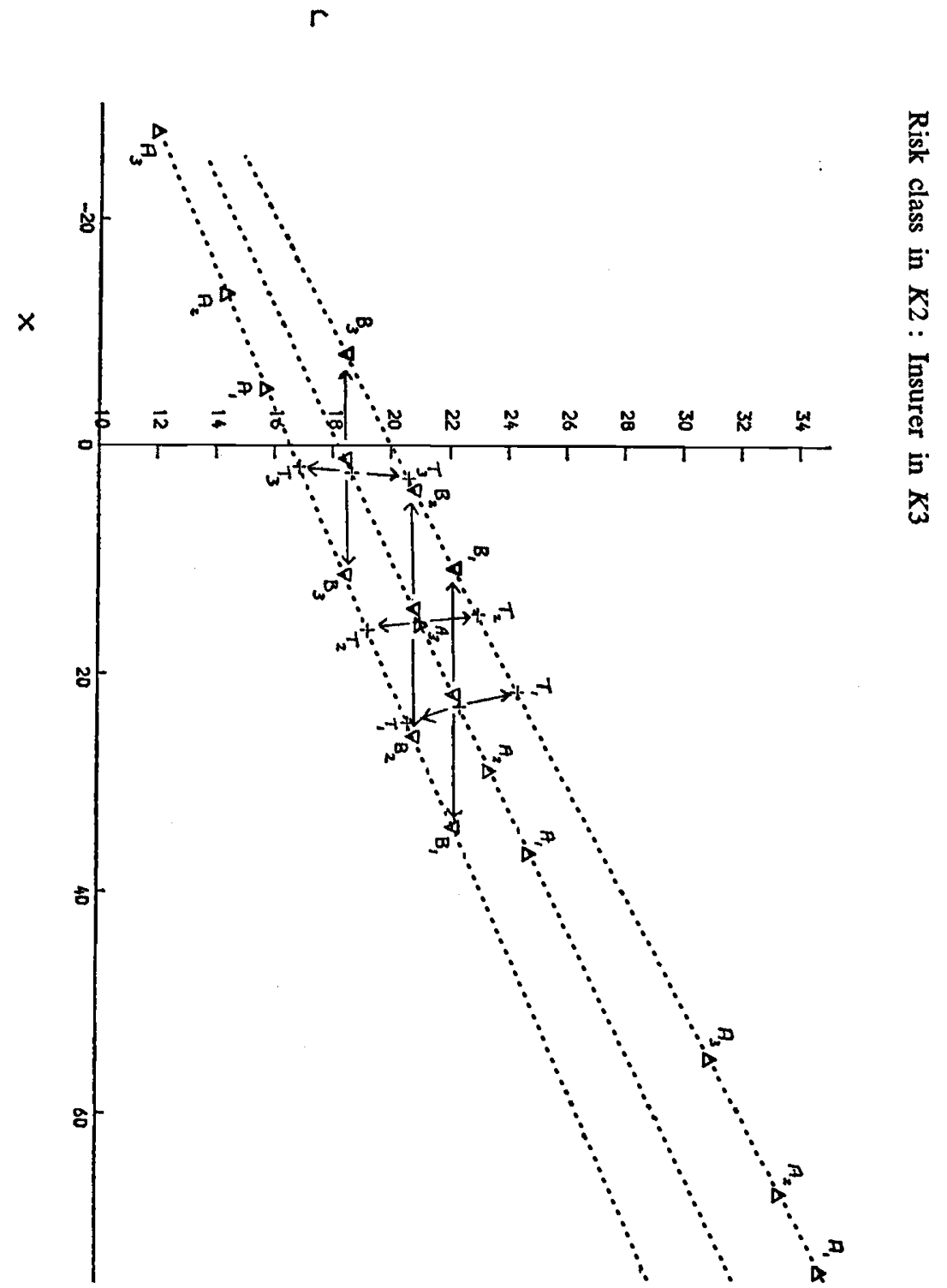

Figure 16 : Results generated by three random number seeds and three different strategies.

Top line: home currency appreciates by $10 \%$

Bottom line: foreign currency appreciates by $10 \%$ 


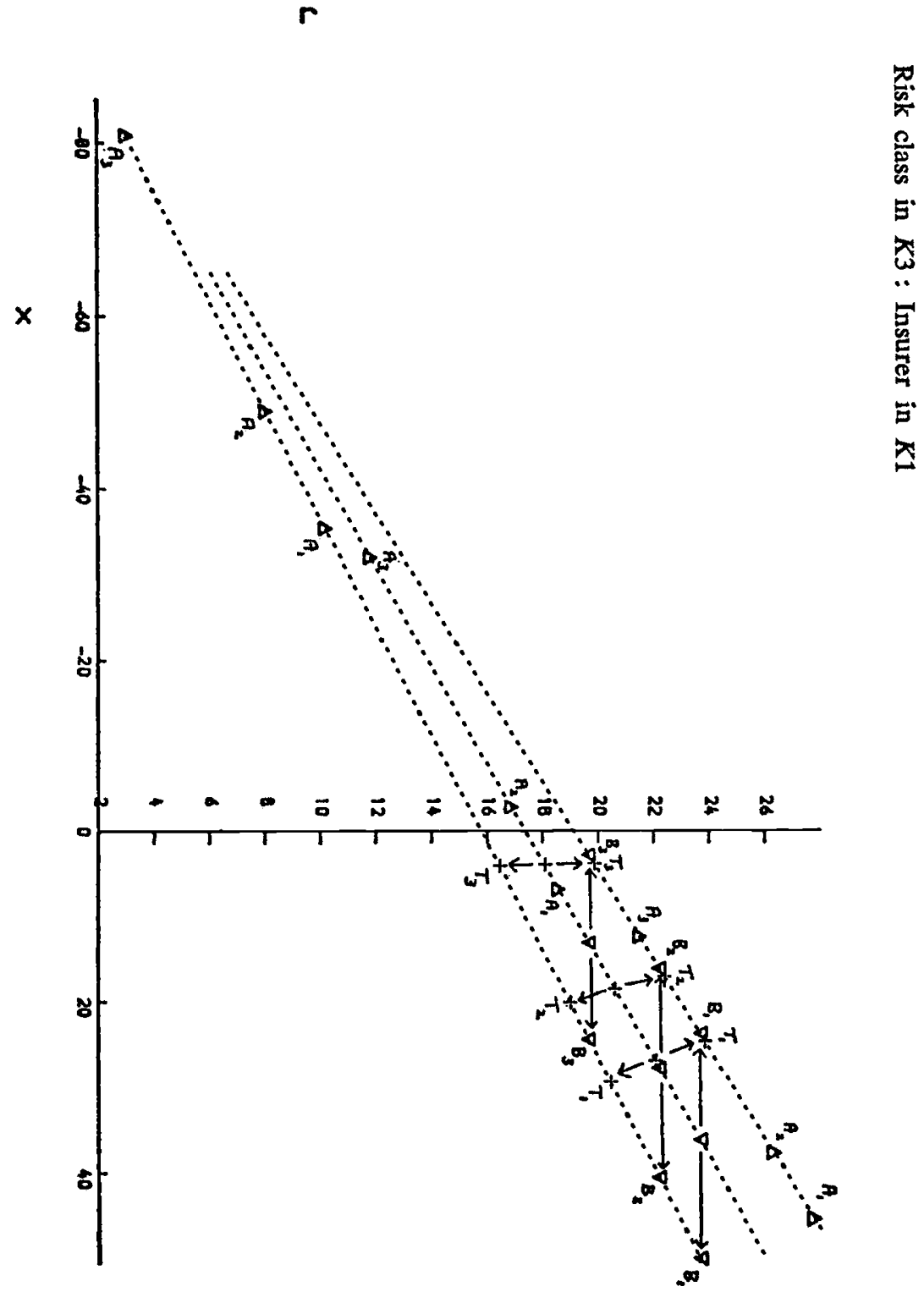

Figure $17:$ Results generated by three random number seeds and three different strategies.

Top line: home currency appreciates by $10 \%$

Bottom line: foreign currency appreciates by $10 \%$ 


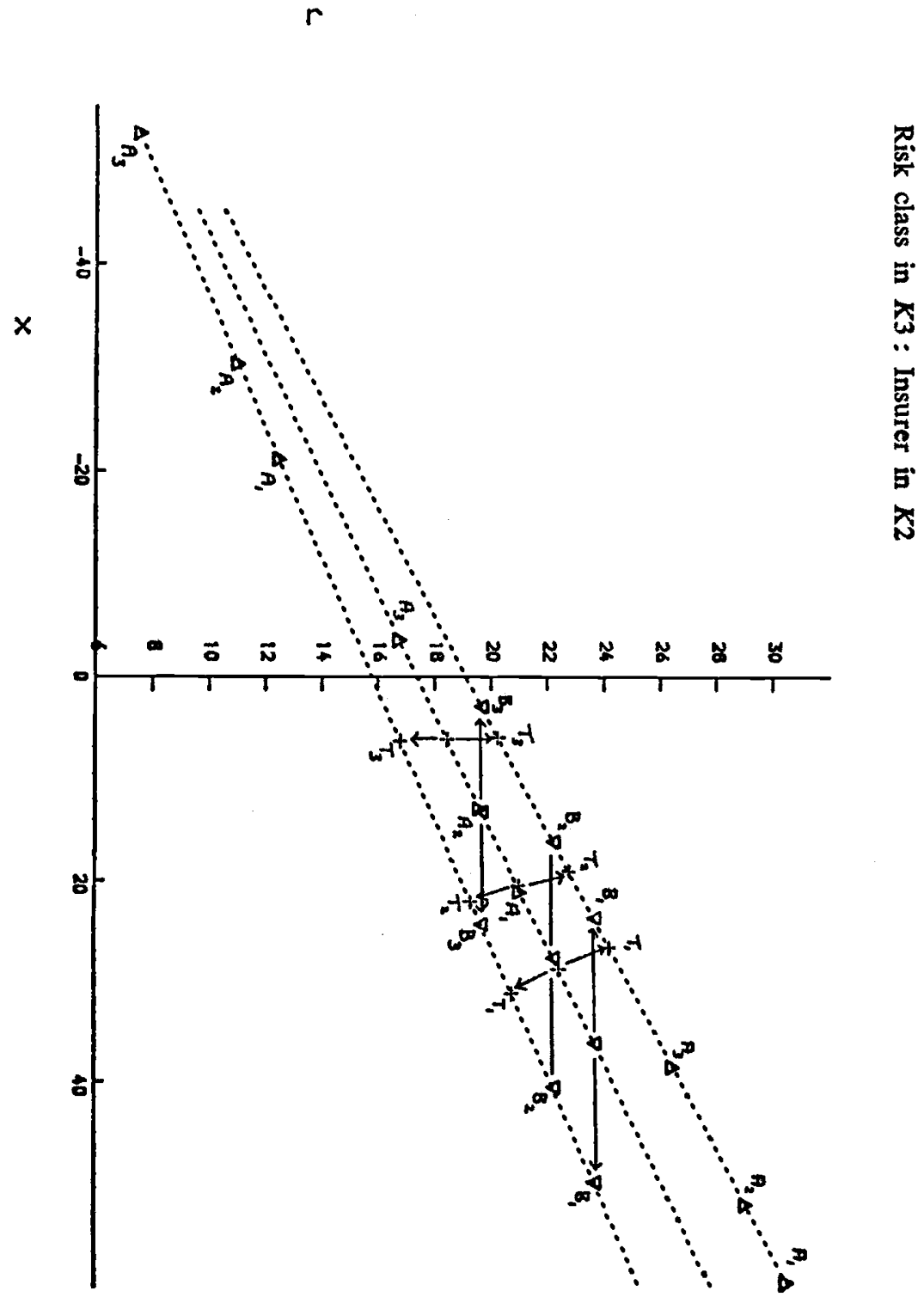

Figure $18:$ Results generated by three random number seeds and three different strategies.

Top line: home currency appreciates by $10 \%$

Bottom line: foreign currency appreciates by $10 \%$ 
were picked at random, were 4529,9121105554 and 9152470272 . These graphs give a clearer idea of the shifts in the results of different strategies caused by fluctuating exchange rates. These shifts have been indicated by arrows for the $B$ and $T$ strategies; the arrows were omitted for the $A$ strategy to avoid confusion, though it should be clear from the labelling which points correspond to which result e.g. $A_{1}$ is the result of strategy $A$ generated by random number seed 1 and $T_{3}$ is the result of strategy $T$ generated by random number seed 3 .

A consistent notation has been used in Figures 7 to 18, with results of strategy $A$ indicated by the symbol $\triangle$, results of $B$ by $\nabla$, and results of $T$ by + . The results in each graph lie on three lines; the middle line $g_{F}$ corresponds to steady exchange rates, while the top and bottom lines, $g_{A}$ and $g_{D}$, correspond to $10 \%$ appreciation of home currency and foreign currency respectively, as in Section 2 . In each set of diagrams the first two graphs (Figures $7,8,13,14$ ) are for the case $K r=K 1$, the next two are for the case $K r=K 2$ (Figures 9, 10, 15, 16), and the last two are for the case $K r=K 3$ (Figures 11, 12, 17, 18).

The general effects of currency fluctuations are discussed in the following subsection 3.1, while 3.2 and 3.3 look at the differences between the $B$ and $T$ strategies, and the $B$ and $A$ strategies, respectively.

\subsection{Some general features of currency fluctuation effects}

Looking first at the gross differences between the various distributions of results as shown in Figures 7 to 12 and Tables 7 and 8, the following features emerge :

(a) The least variation in the $r$ value is given by strategy $B$, in which they remain the same whatever the change in exchange rates, while the greatest variation in $r$ values is given by strategy $A$.

(b) The least variation in the $x$ values is given by strategy $T$, while the greatest variation in $x$ values is again given by strategy $A$.

(c) If the foreign currency appreciates by $10 \%$, the best result is always given by strategy $B$, even if $B$ is inferior to the other two strategies in a steady exchange rate environment.

(d) If the home currency appreciates by $10 \%$, the best result is always given by strategy $A$; conversely if the foreign currency appreciates by $10 \%$, the worst result is always given by strategy $A$.

(e) In strategies $A$ and $T$ the $r$ value shifts upwards if the home currency appreciates by $10 \%$ and shifts downwards if the foreign currency appreciates by $10 \%$.

(f) In strategy $A$ the $x$ value is increased if the home currency appreciates and decreased if the foreign currency appreciates; the converse is true for strategy $B$.

The greater effect of exchange rate fluctuations on the results of strategy $A$ is, of course, due to the fact that foreign assets are not matched initially in $A$, so that a foreign exchange adjustment was added to the shareholders funds at the end of the year, in addition to any post-tax profits. (This does not happen in strategies $B$ and $T$ ). These adjustments were $36.0 \%, 36.2 \%$ and $36.4 \%$ of shareholders funds for the risk class in $K 1, K 2$ and $K 3$ respectively when the home currency appreciated by $10 \%$. 
When the foreign currency appreciated by $10 \%$, the adjustments were $-39.6 \%$, $-39.8 \%$ and $-40.1 \%$. There were also foreign exchange gains or losses in strategy $A$, which did not arise in strategies $B$ or $T$, since funds are transferred to or from the home country at the end of each quarter. However the magnitude of these items was relatively small, typically between $1.5 \%$ and $2 \%$ of shareholders funds.

Item (e), above, in explained by the fact that shareholders funds are held in the home country in strategies $A$ and $T$. Thus when the home currency appreciated, the denominator of the solvency ratio always decreased, while the numerator either increased, or, at worst, decreased by a smaller relative amount. The opposite effects occurred when the foreign currency appreciated by $10 \%$.

Item ( $f$ ) is explained, in the case of strategy $A$, by the relatively large exchange adjustments discussed above. In the case of strategy $B$, the $x$ value in the steady exchange rate environment becomes $x_{A}$ if the home currency appreciates by $100 a \%$ or $x_{D}$ if the home currency depreciates by $100 a \%$ where

$$
\begin{aligned}
& x_{A}=(100+x) /(1+a)-100 \\
& x_{D}=(100+x)(1+a)-100
\end{aligned}
$$

\subsection{Effects of currency fluctuations on $\mathrm{B}$ and $\mathrm{T}$ strategies}

Turning now to the detailed results shown in Figures 13 to 18 it is possible to obtain a better idea of the shifts of $x, r$ values corresponding to different underwriting results. The three chosen random number seeds generated three completely different sets of claims numbers and amounts (at initial prices), thus giving rise to different $x, r$ values. These values were of course dependent on the interest and inflation rates of the simulated countries, but in each case it can be seen, by looking at the order of the points on each $g$ line, that seed 1 always gave the best result and seed 3 the worst result.

Comparison of the results of the $B$ and $T$ strategies in each graph reinforces the implication of the averages calculated in Tables 7 and 8 , namely that when the home currency appreciated by $10 \%$, the $T$ strategy always gave a better result than the $B$ strategy, while the converse was true if the foreign currency appreciated by $10 \%$. This can be seen by looking at the order of the points on the $g_{A}$ and $g_{D}$ lines. However, there are substantial differences in the "cross-over" point, i.e. the level of currency appreciation at which the $T$ strategy becomes the better option. An obvious difference is that if the interest rates are greater in $K r$ than in $K h$, then the cross-over point lies above the $g_{F}$ line ; in other words, the advantage of the greater return on investments in strategy $B$ in a steady exchange rate environment is gradually eroded by the increasing appreciation of the currency of $K h$. Conversely, if the interest rates in $K h$ are greater than those in $K r$, the cross-over point lies below the $g_{F}$ line. The position of the cross-over point within each of these two groups varies, however, with the differential in interest rates and with the random number seed.

The first group comprises the case $K r=K 2, K h=K 1$ and the two cases in which $K r=K 3$ (Figures 15, 17 and 18). The graphs indicate that the cross-over points 
are much closer to the $g_{A}$ line when the interest differential is greatest $(K r=K 3$, $K h=K 1$ ), as one would expect. The effect of different underwriting results is most obvious in the case $K r=K 2, K h=K 1$, where the cross-over point for seed 3 seems closer to the $g_{A}$ line than the cross-over points for the other two seeds. Again, it is intuitively obvious that the very bad underwriting result of seed 3 would need a greater degree of currency appreciation to improve the $T$ strategy result.

The second group comprises the remaining three cases in which $K r=K 1$ (twice) and $K r=K 2, K h=K 3$ (Figures 13, 14 and 17). The cross-over points seem much closer to the $g_{D}$ line when the interest differential is greatest $(K r=K 1, K h=K 3)$, while the other two cases have cross-over points very close to the $g_{F}$ line. The effect of different seeds is shown most clearly when $K r=K 1$, the cross-over point for seed 3 tending to be nearer the $g_{D}$ line than the points for the other two seeds.

It is also possible to look more closely at the directions of the shifts in the strategy results. From Table 7, the average $x$ values of the $T$ results are greatest in the steady exchange rate environment in three cases :

$$
\begin{aligned}
& K r=K 2, K h=K 1 \\
& K r=K 1, K h=K 2 \\
& K r=K 2, K h=K 3
\end{aligned}
$$

Thus in these cases the shift of the average $x$ value from the $g_{F}$ line to the $g_{A}$ or $g_{D}$ lines is always in the negative $x$ direction. In the remaining three cases, the average $x$ value for the $T$ strategy is least in the steady exchange rate environment, so that the shift is always in the positive $x$ direction. Thus on the basis of these results alone it might be thought that different combinations of countries give rise to different shift directions of the $x$ values in strategy $T$. However, the small number of results in the samples make any such inference highly speculative, and it can in fact be seen from Figures 13 to 18 that the direction of the shifts is dependent on the random number seed. For example, when $K r=K 2$ and $K h=K 1$ (Figure 15), the shift of the $x$ value of $T_{1}$, from the $g_{F}$ line to the $g_{A}$ line is negative, while the corresponding shift for $T_{3}$ is positive. It is, however, possible to discern a general pattern of exchange fluctuation effects on the $x$-values ; appreciation of the home currency gives the largest increase in $x$-value for the worst underwriting result (seed 3) and the least increase in $x$-value for the best underwriting result (seed 1), while appreciation of the foreign currency gives the largest increase in $x$-values for seed 1 and the least increase for seed 3 . This can be seen by looking at the slopes of the lines connecting the points $T_{r}(r=1,2,3)$.

\subsection{Comparison of $\mathrm{A}$ and $\mathrm{B}$ strategies}

It is clear from 3.1 that the $A$ strategy is by far the most risky strategy for an insurer, in the sense that much greater variations in results will occur in conditions of fluctuating exchange rates than in strategies $B$ or $T$. Nevertheless, strong currencies do exist, a notable example being the Swiss Franc, and the long term trend is for other currencies to depreciate significantly relative to the strong currency. An insurer based 
in a country with such a currency might then consider seriously strategy $A$ as a possible option, assuming that the rules of the foreign country allow technical reserves to be held in the home country.

Strong currencies are often associated with countries with relatively low, stable levels of infiation and interest rates. It is therefore of interest to estimate the level of home currency appreciation above which strategy $A$ gives a better result than strategy $B$, even if the return on investments in the foreign country is double or triple the return on investments in the home country.

The results of the previous sections for the two cases when $K h=K 1$ and $K r=K 2$ or $K 3$ were investigated in more detail by carrying out further simulation runs for strategies $A$ and $B$ and home currency appreciations of $a \%(a=1,2, \ldots 9)$. The same three random number seeds were used, and the $x$ values obtained from these runs are set out in Tables 9 and 10.

Table 9 : Percentage increase in shareholders funds when $\mathrm{Kr}=\mathrm{K} 3$ and $\mathrm{Kh}=\mathrm{K} 1$ for different currency appreciations and three different random number seeds, strategies A and B

\begin{tabular}{|c|c|c|c|c|c|c|c|}
\hline \multirow{2}{*}{$\begin{array}{c}\text { Apprecia- } \\
\text { tion } \\
\text { of } \\
\text { home } \\
\text { currency } \\
\%\end{array}$} & \multicolumn{2}{|c|}{ RNS I } & \multicolumn{2}{|c|}{ RNS II } & \multicolumn{2}{|c|}{ RNS III } & \multirow{2}{*}{$\begin{array}{l}\text { Foreign } \\
\text { Exchange } \\
\text { Adjustment } \\
\text { as \% of } \\
\text { initial } \\
\text { shareholders } \\
\text { funds }\end{array}$} \\
\hline & $A$ & $B$ & $A$ & $B$ & $A$ & $B$ & \\
\hline 0 & -2.79 & 27.82 & 6.96 & 36.19 & -31.93 & 13.13 & 0 \\
\hline 1 & 1.79 & 26.55 & 11.15 & 34.84 & -27.10 & 12.01 & 3.97 \\
\hline 2 & 6.27 & 25.31 & 15.25 & 33.52 & -22.36 & 10.91 & 7.85 \\
\hline 3 & 10.66 & 24.10 & 19.28 & 32.22 & -17.71 & 9.83 & 11.67 \\
\hline 4 & 14.97 & 22.90 & 23.22 & 30.95 & -13.15 & 8.78 & 15.41 \\
\hline 5 & 19.13 & 21.73 & 27.10 & 29.70 & -8.69 & 7.74 & 19.07 \\
\hline 6 & 23.00 & 20.58 & 30.89 & 28.48 & 4.30 & 6.73 & 22.67 \\
\hline 7 & 26.80 & 19.46 & 34.61 & 27.28 & 0 & 5.73 & 26.20 \\
\hline 8 & 30.52 & 18.35 & 38.27 & 26.10 & 4.21 & 4.75 & 29.67 \\
\hline 9 & 34.18 & 17.27 & 41.85 & 24.94 & 8.35 & 3.79 & 33.07 \\
\hline 10 & 37.76 & 16.20 & 45.37 & 23.81 & 12.41 & 2.85 & 36.40 \\
\hline
\end{tabular}


Table 10 : Percentage increase in shareholders funds when $\mathrm{Kr}=\mathrm{K} 2$ and $\mathrm{Kh}=\mathrm{K} 1$ for different currency appreciations and three different random number seeds, strategies $\mathrm{A}$ and $\mathrm{B}$

\begin{tabular}{|c|c|c|c|c|c|c|c|}
\hline \multirow{2}{*}{$\begin{array}{c}\text { Apprecia- } \\
\text { tion } \\
\text { of } \\
\text { home } \\
\text { currency } \\
\%\end{array}$} & \multicolumn{2}{|c|}{ RNS I } & \multicolumn{2}{|c|}{ RNS II } & \multicolumn{2}{|c|}{ RNS III } & \multirow{2}{*}{$\begin{array}{l}\text { Foreign } \\
\text { Exchange } \\
\text { Adjustment } \\
\text { as \% of } \\
\text { initial } \\
\text { shareholders } \\
\text { funds }\end{array}$} \\
\hline & $A$ & $B$ & $A$ & $B$ & $A$ & $B$ & \\
\hline 0 & 0.34 & 14.28 & 7.91 & 21.85 & -25.40 & 1.17 & 0 \\
\hline 1 & 4.52 & 13.15 & 12.01 & 20.64 & -20.76 & 0.17 & 3.95 \\
\hline 2 & 8.61 & 12.04 & 16.03 & 19.46 & -16.21 & -0.81 & 7.81 \\
\hline 3 & 12.63 & 10.95 & 19.98 & 18.30 & -11.75 & -1.78 & 11.60 \\
\hline 4 & 16.56 & 9.88 & 23.84 & 17.16 & -7.38 & -2.72 & 15.33 \\
\hline 5 & 20.42 & 8.84 & 27.63 & 16.05 & -3.10 & -3.65 & 18.98 \\
\hline 6 & 24.21 & 7.81 & 31.35 & 14.95 & 1.11 & -4.56 & 22.56 \\
\hline 7 & 27.92 & 6.80 & 35.00 & 13.88 & 5.23 & -5.45 & 26.07 \\
\hline 8 & 31.57 & 5.81 & 38.58 & 12.82 & 9.28 & -6.32 & 29.52 \\
\hline 9 & 35.15 & 4.84 & 42.09 & 11.79 & 13.26 & -7.18 & 32.90 \\
\hline 10 & 38.66 & 3.89 & 45.54 & 10.77 & 17.16 & -8.03 & 36.22 \\
\hline
\end{tabular}

Table 9 displays the results in the case of the greatest differential between interest rates, when $K h=K 1$ and $K r=K 3$, so that the return on investments in strategy $B$ was three times the return on investments in strategy $A$. It can be seen that the crossover point for seeds 1 and 2 occurs when the home currency appreciates by between 5 and $6 \%$, since the $x$ values for strategy $A$ are greater than those for strategy $B$ for currency appreciation of $6 \%$ or more. This is a remarkably consistent result considering the difference between the $x$ values in the steady exchange rate environment. For seed 3 the cross-over point occurs at a currency appreciation of between 8 and $9 \%$ but this is for an unusually bad set of underwriting results.

Table 10 displays the results in the case $K h=K 1$ and $K r=K 3$, so that the return on investments in strategy $B$ was twice the return on investments in strategy $A$. It can be seen that the cross-over point for seeds 1 and 2 occurs when the home currency appreciated by between 2 and $3 \%$. For seed 3 , the home currency has to appreciate by almost $5 \%$ for strategy $A$ to give a better result. 
These results suggest that an appreciation of the home currency of the same order of magnitude as the interest differential will always give a better result if strategy $A$ is adopted in preference to strategy $B$, and an appreciation of home currency of half this magnitude will favour strategy $A$ as long as the underwriting losses are not unusually large. This demonstrates the advantages to insurers of being based in a country with strong currency and a stable economic environment.

\section{Appendlx}

Determination of risk class parameters

The data on which the numerical estimates were based are a claim settlement analysis of claims incurred in 1971 in a Property Risk Class (Risk Group Fire) underwritten in the U.S.A. by a U.K. insurer. The total number of claims attributable to the year of origin was given as 7,518 and the numbers and amounts of claims settled in each year are set out in Table A.1.

Table A.I : Numbers and amounts of claims settled from 1971 claims settlement analysis (amounts in $£$ sterling)

\begin{tabular}{|c|c|c|c|c|c|}
\hline \multirow{2}{*}{\multicolumn{2}{|c|}{$\begin{array}{l}\text { Financial } \\
\text { Year }\end{array}$}} & \multicolumn{2}{|c|}{$\begin{array}{l}\text { Number of claims } \\
\text { closed in the year }\end{array}$} & \multirow{2}{*}{$\begin{array}{l}\text { Amount of } \\
\text { payments made } \\
\text { in the year }\end{array}$} & \multirow{2}{*}{$\begin{array}{l}\text { Amount of } \\
\text { payments made } \\
\text { up to the end } \\
\text { of the year }\end{array}$} \\
\hline & & $\begin{array}{l}\text { at no } \\
\text { cost }\end{array}$ & $\begin{array}{l}\text { at some } \\
\text { cost }\end{array}$ & & \\
\hline 1971 & 1 & 89 & 6183 & $2,241,063$ & $2,241,063$ \\
\hline 1972 & 2 & 290 & 727 & $1,328,941$ & $3,570,004$ \\
\hline 1973 & 3 & 13 & 83 & 314,193 & $3,884,197$ \\
\hline 1974 & 4 & 1 & 86 & 153,824 & $4,038,021$ \\
\hline 1975 & 5 & 0 & 29 & 107,852 & $4,145,873$ \\
\hline 1976 & 6 & 0 & 1 & 2,754 & $4,148,627$ \\
\hline 1977 & 7 & 0 & 5 & 9,650 & $4,158,277$ \\
\hline
\end{tabular}

The data also included payments on account but since these were a very small proportion of any year's total payments they have been ignored for the purposes of this study, and each year's payments are assumed to be for claims finally settled in that year. 
It can be seen that the data are incomplete, because no information was available about claims settled after 1977 ; however the estimated number of claims outstanding at the end of year 7 was given as 11 , and the estimated amount outstanding as 15,367 , both of which are negligible compared to the total numbers and amounts of claims incurred. In fact, from Table A.1 it can be seen that the amount of claims outstanding at the end of year 5 (including the estimate for outstanding claims at the end of year 7) is only $0.5 \%$ of the total aggregate claims payments. It was therefore decided to simulate the truncated claims settlement and base the numerical estimates on the 7,108 non-zero claims incurred in year 1 and settled by the end of year 5 . This meant that the maximum time between incurrence and settlement of a claim must be 4 years.

It was also decided to use the option of inputting claims data as histograms rather than as theoretical probability distributions. The ASIR model requires two histograms, one for the amounts of claims at initial prices and one for the times between incurrence and settlement. (Claims are always assumed to be incurred uniformly throughout each simulated period and the times between incurrence and settlement are correlated with the claims amounts.) Ideally these would be based on detailed information about claims available in an insurance company's data files. In this case, only the aggregated information contained in the claims settlement analysis was available so it was necessary to make some assumptions about the types of claims likely to occur.

It was hypothesised that the vast majority of claims in this risk class would be small, arising from localized fire damage, and settled within a couple of months of incurrence. This is confirmed by the large percentages of the total number of claims settled by the end of years 1 and 2, as shown in Table A.2. A small proportion of claims would be large, arising from total loss of the property, and the claims amounts in these cases would depend on the insured values, which would themselves tend to be mainly within the range of average property values, but with a long and potentially dangerous "tail" of a few expensive properties.

Table A.2 : Cumulative percentages of numbers of non-zero claims and aggregate payments derived from Table A.1

\begin{tabular}{|ccccc|}
\hline & & \multicolumn{3}{c|}{ Aggregate payments } \\
\cline { 3 - 5 } Year & $\begin{array}{c}\text { Number of } \\
\text { claims settled }\end{array}$ & Actual & $\begin{array}{c}\text { Discounted } \\
\text { at 5\% }\end{array}$ & $\begin{array}{c}\text { Discounted } \\
\text { at } 10 \%\end{array}$ \\
\hline 1 & 87.0 & 54.1 & 55.8 & 58.1 \\
2 & 97.2 & 86.1 & 87.4 & 90.0 \\
3 & 98.4 & 93.7 & 94.5 & 96.8 \\
4 & 99.6 & 97.4 & 97.8 & 99.8 \\
5 & 100.0 & 100.0 & 100.0 & 100.0 \\
\hline
\end{tabular}


It was also necessary to make some estimate of the payments in the claims settlement anlysis data in terms of year 1 prices. This meant allowing both for inflation and for the effects of fluctuating exchange rates, since the data are in terms of $£$ sterling, whereas ASIR requires claims amounts data in terms of the currency of the country where the risks arise. The payments were therefore discounted at yearly rates of $5 \%$ and $10 \%$ to give some idea of the likely distribution of claims amounts at constant prices, and the cumulative percentages of claims payments thus calculated are shown in Table A.2. The data are, in any case, only one sample from what is probably a highly variable claims distribution, so it is unrealistic to aim for more than a reasonably good fit to the cumulative percentages of discounted claims amounts and claims numbers of years 1 and 2 .

The estimated histograms actually used in the simulations are set out in numerical form in Tables A.3 and A.4. The numbers were obtained by trial and error, based on the above assumptions, and by running the ASIR model with different numerical inputs for the band widths and percentages until the best fit was achieved for the cumulative claims amount percentages. These are shown in Table A.5, where the estimated cumulative percentages were obtained from the generation of 200 claims at the midpoint of each week of the simulated year corresponding to the cumulative probabilities in the histograms of $.0025+n / 100$ and $.0075+n / 100 \quad(n=0,1$, $\ldots$, , 99). Linear interpolation was used in both histograms.

Table A.3 : Estimated histogram of claims amounts at initial prices

\begin{tabular}{|rrrr|}
\hline Band & $\begin{array}{c}\text { Lower } \\
\text { Limit }\end{array}$ & $\begin{array}{c}\text { Upper } \\
\text { Limit }\end{array}$ & $\begin{array}{c}\text { Percentage } \\
\text { of claims } \\
\text { in band }\end{array}$ \\
\hline 1 & 200 & 1000 & 38.00 \\
2 & 1000 & 2500 & 58.00 \\
3 & 2500 & 7000 & 0.20 \\
4 & 7000 & 9000 & 1.00 \\
5 & 9000 & 9250 & 2.10 \\
6 & 9250 & 9500 & 0.50 \\
7 & 9500 & 10000 & 0.05 \\
8 & 10000 & 20000 & 0.05 \\
9 & 20000 & 50000 & 0.05 \\
10 & 50000 & 100000 & 0.05 \\
\hline
\end{tabular}


Table A.4: Estimated histogram of times between incurrence and settlement in years

\begin{tabular}{|cccc|}
\hline Band & $\begin{array}{c}\text { Lower } \\
\text { Limit }\end{array}$ & $\begin{array}{c}\text { Upper } \\
\text { Limit }\end{array}$ & $\begin{array}{c}\text { Percentage } \\
\text { of claims } \\
\text { in band }\end{array}$ \\
\hline 1 & 0 & 0.41 & 96.2 \\
2 & 0.41 & 0.50 & 0.5 \\
3 & 0.50 & 1.00 & 0.2 \\
4 & 1.00 & 1.50 & 0.7 \\
5 & 1.50 & 2.50 & 1.7 \\
6 & 2.50 & 4.00 & 0.7 \\
\hline
\end{tabular}

Table A.5 : Comparison of actual claims payments discounted at $10 \%$ per year with estimated claims payments at constant prices

\begin{tabular}{|ccc|}
\hline & \multicolumn{3}{c|}{ Cumulative Percentages } \\
\hline Year & Data & Estimated \\
\hline 1 & 58.5 & 59.5 \\
2 & 90.0 & 86.4 \\
3 & 96.8 & 95.2 \\
4 & 99.8 & 98.6 \\
5 & 100.0 & 100.0 \\
\hline
\end{tabular}

It was decided to simulate a constant number of 70,000 policies in the risk class, with the average number of claims in a year equal to $10 \%$ of the number of policies. Thus the expected number of claims was approximately equal to the number of nonzero claims in the claims settlement data. It was also thought that the nature of the risk class might lead to greater variability in the number of claims than that given by the standard Poisson distribution, so the Negative Binomial distribution was specified, with the variance $8 \%$ greater than the mean. Of course, this variance, and the "tail" of the claims amount histogram are based entirely on guesswork, and may give rise to wider variations in the simulated results than may actually be the case. 
The remaining risk class parameters were mainly related to expenses, the major item being commission of $25 \%$ on renewed policies. The overall claims ratio was just over $28 \%$, on average. The average time delays between accounting for, and receipt of, premiums and commissions were taken as .075 and 0.85 years respectively.

Premium rates were assumed to be changed at the beginning of each year, being increased by the (constant) inflation factor, and all the simulations were run with four periods in a year.

\section{REFERENCES}

1. BROWN, Z. M., and GALITZ, L.: "The ASIR System User's Manual", Etudes et Dossiers Nr. 52, Association de Genève (November 1981).

2. LLOYD, C. G.: "Can the EMS solve insurers' currency problems?", paper presented to the conference of U.K. Insurance Economists, Nottingham University (1980). 